\title{
ATTITUDES OF YOUTH TOWARD READING BEFORE AND AFTER A MOTIVATIONAL PROJECT
}

\author{
Shirley A. Fitzgibbons \\ Indiana University \\ School of Library and Information Science \\ Bloomington, IN 47405 USA \\ E-mail: fitzgibb@indiana.edu
}

\begin{abstract}
As part of an evaluation project assessing the impact of a specific reading motivation program in 30 schools (20 elementary, 10 middle), a longitudinal study of student reading attitudes was conducted using the nationally-tested Elementary Reading Attitude Survey instrument. The instrument tested both attitudes toward recreational reading and school reading. The results have implications for types of reading programs as well as book access and use of libraries.
\end{abstract}

\section{BACKGROUND}

\section{Introduction}

Recently, more attention has been paid to the need to motivate and encourage reading in addition to the teaching of reading skills. The landmark publication, Becoming a nation of readers: The report of the Commission on Reading, concluded that "Among all the ways the children reported spending their leisure time, average minutes per day reading books was the best predictor of reading comprehension, vocabulary size, and gains in reading achievement between the second and fifth grade." (Anderson, Hiebert, Scott, \& Wilkinson, 1985, p.77) Personal, independent reading, either in school or out-of-school, is extremely important; yet most studies have shown that "...the amount of time children spend reading in the average classroom is small" ( 7 or 8 minutes or less than $10 \%$ of the total time devoted to reading) (Anderson et al., p. 76); and "... most children don't read very much during their free time... (about 1\% of their free time)." (p. 77) In that same report, several factors are identified as important in the creation of readers including home environments (especially reading aloud to young children as readiness for learning to read), and the use of reading instructional time in school. One of the primary objectives of the "whole language" and "literature across the curriculum" movements has been to encourage more independent reading.

Consequently, school personnel need to know what factors affect student reading attitudes and behaviors so that they can more successfully motivate students to read. McKenna, Kear, and Ellsworth (1995) present a rationale for the importance of research on student reading attitudes:

Understanding the role of attitude in developing readers is important for two principal reasons. First, attitude may affect the level of ability ultimately attained by a given student through its influence on such factors as engagement and practice. Second, even for the fluent reader, poor attitude may occasion a choice not to read when other options exist, a condition now generally known as aliteracy. (p. 934)

Attitudes are acquired through experience, can be observed through behavior, and persist over time. It is important to acknowledge that attitude is a learned response which is influenced by many environmental factors such as home, school, and peers. Initially thought to be more of a cognitive aspect, today most social psychologists consider attitude to be related to several affective aspects suchas the individual's self-esteem, values, feelings, and interests (Cothern \& Collins, 1992). Several researchers have explored the relationship between reading attitudes and achievement; generally results have shown that low achievement correlates positively with a negative attitude toward reading 
(Cothern \& Collins). Attitudes have been shown to decline from a positive attitude in primary grades to a negative attitude in the upper grades and secondary grades (Alexander \& Filler, 1976). Student attitudes toward reading are important; educators and librarians, knowing that attitudes toward reading are learned responses, need to determine the types of motivation that might improve attitudes and consequently, reading behaviors and achievement.

\section{Purpose and Questions}

This report includes the results of one part of a series of studies in a major investigation of students' reading. An innovative project, Project REAP (Reading Excitement and Paperbacks Project), administered by the Indiana Department of Education and funded by the Lilly Endowment, included several phases of a "books in schools" special project in Indiana public schools implemented between 1988 and 1995. This particular study was part of the Evaluation Study of the REAP 3 project conducted between 1993 and 1995.

Children and young adults in grades four through eight in 30 schools were involved in the project including 20 elementary schools and 10 middle/junior high schools. Each elementary school received a $\$ 7000$ grant and each middle school received a $\$ 14,000$ grant for two purposes: purchase of a large number of paperback books for libraries and classrooms and for initiation of several school motivational innovations to encourage reading. At the beginning of the project, preview collections were brought to each school for students and teachers to help choose their school's REAP book collections. For the REAP 3 phase of the project, the following activities were specifically encouraged by the REAP project director:

(1) classroom collections of books;

(2) initiation of Sustained, Silent Reading (SIR);

(3) teacher read-alouds;

(4) special reading motivational activities.

The REAP 3 evaluation study of this project included five case study school reports based on onsite school observations and a series of interviews, a mail questionnaire to all teachers and other relevant school personnel, and testing of students' attitudes toward reading. Only the attitudinal part of the evaluation study will be included in this report.

The study's purpose was to assess students' feelings (attitudes) about reading both in school and for recreational purposes. Several questions directed the focus of the study including:

(1) Did the activities of the REAP 3 project over a two-year time period affect attitudes toward reading?

(2) Are there differences between grade levels in reading attitude scores: total scores, recreational reading scores, or academic/school reading attitude scores? Are there differences between elementary school students and middle school students on these scores?

(3) Are there differences between genders in reading attitude scores: total scores, recreational reading scores, or academic/school reading attitude scores?

(4) Are there differences between schools on student reading attitudes?

Gender, grade level, and school served as the independent variables in the study in relationship to the dependent variables of attitude test scores (both pretest and post-test) and two subscales of the test, attitude toward recreational reading and attitude toward school reading. Ideally, data would have been obtained on student ability levels (reading test scores) as a background variable. Although this was initially considered, it was not feasible for several reasons: there were large numbers of respondents from many schools, making it a burdensome administrative task for the schools; Indiana students do not take a standardized reading test at each of the respondents' grade levels; and the scores would only be useful for students with matching pretests and post-tests.

\section{REVIEW OF RELATED RESEARCH}

Research on reading attitudes was fully reviewed by Alexander and Filler (1976), identifying important variables which are related to reading attitudes such as self-concept, parental influence and home environment, teachers and classroom atmosphere, gender, intelligence, achievement, socioeconomic status, and student interests. Research by others (Greenberg, 1970; Walberg \& Tsai, 1985; McKenna et al., 1995) has supported the salience of certain variables. 
Several researchers have developed conceptual models of attitudes toward reading (Mathewson, first developed in 1985 and revised in 1994; Ruddell \& Speaker, 1985; Liska, 1984; McKenna et al., 1990, 1995). These models have included both cognitive and affective aspects such as feelings about reading, readiness for reading, and evaluative beliefs about reading. Mathewson viewed attitude as a causal agent both in the decision to read and during the process of learning to read. Liska identified three factors which affect attitude: the readers' beliefs about reading and its outcomes; the act of reading itself; and the reader's beliefs about the social expectations of others and the motivation to conform to them (taken from McKenna, 1994). McKenna builds on this model and suggests the importance of three major areas: beliefs about subjective norms (culture, home, peer group, environmental factors); beliefs about the outcomes of reading (environmental, competing feelings about other activities); and the effect of reading experiences-both direct and indirect. Several researchers suggest that there are interactions among social, environmental, and affective states in the acquisition of reading attitudes.

Many researchers agree that motivation is related to attitude and several of them have identified what appear to be "powerful motivators" in home, school, and peer environments. Most of the studies have used standardized reading attitude instruments to try to relate attitudes to aspects such as gender, ability, achievement, and self-concept. Several motivators which have been identified include role models, providing time to read, having reading choices, and sharing reading with "book buddies" (Bromley, 1994). Cramer and Castle's 1994 book, Fostering the love of reading: The affective domain in reading education, presents "a collection of articles that represent the best in current thinking about a wide range of issues related to reading motivation." (p. v) McKenna's chapter, "Toward a Model of Reading Attitude Acquisition," reviews prior models of Mathewson, Liska, Fishbein and Ajzen, and proposes a new model based on their work and previous research. McKenna's model shows each causal relationship, and then discusses the supporting research in four main areas: beliefs about subjective norms; beliefs about the outcomes of reading; and the effects of reading - both direct effect of reading experiences and indirect effect on reading attitudes. Some sample research findings documented by McKenna on "subjective norms" include:

(1) In the United States, evidence abounds that girls tend to harbor more positive attitudes toward reading than do boys.

(2) The pattern of girl dominance may also be related to achievement. Evidence that girls

establish and sustain an early advantage in reading ability suggests that sex-based differences in attitude may derive from differences in ability.

(3) The relationship of ability to attitude is well documented.

(4) The range of environmental pressures that affect reading attitude acquisition includes:

- differences among students in grades three to five depending on whether they lived in a university town, the inner city, or a rural setting (scores were successively lower in this order);

- kindergarteners had already reached relatively well-informed attitudes even before schooling (based on) the frequency of being read to at home and the extent to which parents modeled reading as a leisure activity;

- positive relationships between reading attitude and socioeconomic status. (McKenna, 1994, pp. 32-33)

Concerning beliefs about the outcomes of reading, McKenna suggests, in his model, that attitude is influenced by beliefs about what will happen if an individual engages in reading based on both environmental factors and prior reading experiences. Some examples of research findings he presents about these beliefs include:

(1) Dissatisfying results will lead to successively worsened attitudes (and the reverse).

(2) Though positive reading experiences may result in more positive attitudes, this will happen only if environmental factors are positive.

(3) As children grow older, more leisure alternatives are open to them, and reading must compete, often causing the attitude of even the successful reader to be subject to decline during higher grade levels.

(4) It is clear that certain practices can be effective in halting or reversing the decline, 
such as reading aloud to students, using high-quality literature, avoiding denigrating reading-group placement, providing metacognitive training, openly discussing students' beliefs, stressing links between literature and students' lives, and using questions to activate prior knowledge. (McKenna, 1994, pp. 33-34)

McKenna (1994) also presents research evidence of direct and indirect effects of reading:

(1) A teacher can influence attitude positively in indirect ways; for example, by establishing a library corner in the classroom and providing opportunities to use it.

(2) The prospect of rewards can have a direct impact on intentions by reducing the attractiveness of competing options and increasing the probability that a student will decide to read. (p. 35)

$\mathrm{He}$ is careful to point out that "Little evidence exists concerning the efficacy of incentive programs in changing reading attitudes. There is little doubt, however, that they can change behavior and induce students to read." (p. 35) His model predicts that these rewards (incentives) may improve attitude when other conditions are met; for example, whether it was a successful reading experience.

The use of reading "histories" by Carlsen and Sherrill (1988) caused them to suggest that positive influences in creating readers included the availability of books, being read to, having role models, having choices of reading materials, and having opportunities to share reading. Anderson, Wilson, and Fielding (1988) identified several factors in the school setting as influential in making readers: access to books; use of incentives/awards; reading aloud, and providing time to read in school. Johnson and Gaskin (1992) provided evidence that use of a variety of instructional strategies, including the acceptance of students' opinions and choice, could produce positive results. Many of these activities (access to books, student choice of books, use of incentives/awards, teachers reading aloud, and more time to read in school), were initiated in the 30 schools as part of the REAP project.

\section{Reading Attitude Instruments}

There have been many attempts to design and test instruments to measure reading attitudes of elementary school students, including the work of Estes (1971), Heathington (1979), Dulin (1979), Tunnell, Calder, and Justen (1988), and more recently, McKenna and Kear (1990), McKenna, Kear, and Ellsworth (1995). Tunnell called for the need for a "quick and reliable method of assessing student reading attitudes that will efficiently measure attitude changes as a result of specific classroom strategies." (p. 147) After constructing and testing such a reading attitude instrument, he suggested, "one should not expect students to have poor attitudes toward reading. It may be that even average or below average readers still have neutral or slightly favorable attitudes." (p. 147) Earlier, Estes had recommended administering such a scale on a pretest and post-test basis (October and May) so the teacher can note changes in attitude toward reading (Estes, 1971). McKenna and Kear (1990) reported on the development of their instrument called the Elementary Reading Attitude Survey (ERAS); their research with the instrument both produced standardized scores, and tests of validity and reliability. They tested the ERAS with 18,128 elementary school students from 95 school districts representing 38 states, with representative subjects on the basis of gender and ethnic distribution, and with estimates of each student's reading ability. The ERAS instrument was chosen for the current study and will be described more fully in a later section.

Studies using these instruments have examined reading attitudes and behaviors of students for the purpose of learning whether they are motivated to read and the factors relating to different levels of motivation. Alexander and Filler (1976) found that attitudes declined steadily from a generally favorable attitude in the early grades to a generally neutral to poor attitude in the secondary grades. McKenna, Kear, and Ellsworth (1995) also found that attitudes decline over the elementary grades. McKenna concludes: “...as children mature and as more and more leisure options compete with reading, positive attitudes toward reading will on average worsen." (p. 941) McKenna found that girls have more positive attitudes than boys. Constant failure in reading and its relationship to selfconcept has been identified as a deterrent to positive reading attitudes (Alexander \& Filler, 1976; Cothern \& Collins, 1992).

Most of this research has been done by reading experts and educational researchers without much consideration of the book access factor which could be operationalized by measures such as the use and quality of school and public libraries, and access to classroom collections. Only a few studies which have tested reading attitudes have also examined specific classroom reading activities such as: giving time for reading, having teachers read aloud, and promoting reading role models. 
Most studies have, at most, examined one factor such as "book floods," instituting time for reading in school through Sustained Silent Reading (SIR), or providing classroom libraries (mostly in primary classrooms). Several researchers have validated tests of reading attitudes with measures such as children's use of the library (often measured by having library cards) or reading scores.

Several factors which this researcher has identified, in two previous reading motivation studies (Fitzgibbons, REAP 1 Evaluation Study, 1990; REAP 2 Evaluation Study, 1993), as important in the motivation of readers include:

(1) access to attractive and popular books;

(2) student involvement in selection of books;

(3) provision of time and encouragement of reading during school day;

(4) use of incentive and award programs;

(5) creation of a reading/literacy environment in the school and home;

(6) recognition of role models including parents, siblings, teachers, librarians, peers, and "celebrities."

In other studies, these factors have been shown to be more or less significant dependent on grade level, gender, and the ability of the student. Certain factors such as teacher behavior, classroom atmosphere, and type of reading instruction have not been sufficiently controlled in many of these studies, and can only be suspected of being related to student reading attitudes and behaviors. More research is needed to show relationships of background variables (home, environment, and classroom) and individual student variables (gender, ethnicity, and ability) on reading attitudes and behaviors.

\section{METHODOLOGY}

\section{Description of the Instrument}

Reading attitudes of students were measured by a standard instrument, the Elementary Reading Attitude Survey (ERAS), which tested two different dimensions of reading attitudes: recreational reading and academic/school reading. The ERAS instrument was chosen for several reasons: it had novelty appeal in its use of the cartoon character, Garfield, who is familiar and interesting to a broad age group; it was easy to introduce and complete; the developer had computed national norms for grades 1 through 6; and it had been tested for reliability and validity in previous studies. Permission to use the instrument had already been granted. The ERAS uses a "meaningful, attention-getting, student-friendly response format" (McKenna \& Kear, 1990, p. 627) depicting the cartoon character in four facial/body expressions (very happy to very unhappy) as a way of responding to a series of statements about reading which begin with the phrase, "How do you feel about...." The ERAS is a 20-item, 4-node, pictorial rating scale. There are two subscales (each with ten items), one measuring recreational reading, the other measuring attitude toward reading for academic/school purposes. Each item is scored from 1 to 4 represented by Garfield's frowning face (1) to a broadly smiling Garfield face (4). The instrument uses a summated rating scale similar to a Likert scale. According to McKenna and Kear, "the decision to use an even number of scale nodes, thus avoiding a neutral middle choice, was based on research suggesting that subjects often use a middle option to avoid committing themselves, even when clear opinions exist." (1995, p. 944) Total scores can range from 10 points (least positive attitude) to 40 points (most positive attitude) on each subscale or 20 to 80 on the combined score. McKenna and Kear had found that the two subscale scores, recreational and academic (school) reading attitudes, were moderately correlated ( $\mathrm{r}=.64$, McKenna \& Kear, 1990).

Although the instrument was not designed for use with students in grades above grade 6, it seemed appropriate for grades 7 and 8 as well, thus providing one instrument to be used with both the elementary and middle school students for comparability purposes. A few questions on the instrument may be less appropriate for the older students. A copy of the instrument and directions for its use can be found in McKenna and Kear's 1990 article.

\section{Procedures}

The REAP 3 project began in Fall 1993 and continued throughout two years, ending in Spring 1995. The decision was made to use pretesting and post-testing to assess student reading attitudes, with the two testing times matching the initiation of the project and its conclusion (Fall 
1993, late Spring 1995). All students in the appropriate grades (grades 4-7) in the selected 20 elementary schools and 10 middle schools participated in the pretest during Fall 1993 as the project was initiated. Instruments and directions were sent to each school by the REAP project director with instructions to return them to the same office. Only students who would be in the school/project for the two years were given pretests (for example, in elementary schools, only grades 4 and 5 if the school included sixth grade).

In the analysis, students are identified by their pretest grade; it is important to recognize that each respondent completed a post-test two full academic years later. For example, fourth graders took the pretest early in their fourth-grade year and completed the post-test at the end of their fifth-grade year. Individual responses were transferred to coding forms and several scores were computed: one for recreational reading, one for academic (school) reading, and a total score. For the elementary school respondents, standardized scores (percentile rankings) had been compiled by the instrument developer, but since there were no comparable scores for seventh and eighth-grade students, this ranking was not used.

\section{Response Rate}

The return rate was excellent since the attitude testing was considered part of the evaluation of the total REAP project. However, due to the characteristics of these schools with "at risk" students (with high mobility and absenteeism), probably only one-half of the instruments could be matched with pretest to post-test. Even with this problem, instruments were received and matched for 26 schools (17 elementary and 9 middle schools). Instruments were never received from two elementary schools, and another elementary school's respondents had to be eliminated because pretest and posttest could not be matched (only first names were written on tests). Responses from one middle school were excluded from the multivariate analysis due to the low number of respondents. All instruments with several missing responses were also excluded at the time of the coding since total mean scores could not be computed for those respondents.

A total of 2410 matched instruments were available for analysis. There were 901 student respondents from elementary schools, 441 girls and 460 boys, with the following breakdown by grade level: 673 fourth graders and 228 fifth graders (grades at pretest time). There were 1509 student respondents from middle schools, 822 girls and 687 boys, including 180 fifth graders, 443 sixth graders, and 886 seventh graders.

\section{Statistical Analysis}

Two separate analyses were completed: one for elementary schools and one for middle schools. Two statistical procedures were used. First, descriptive statistics with means and standard deviations were computed using SPSS-PC program (version 6.1), producing bar graphs to display the three sets of mean scores (recreational attitude, academic/school attitude, and full reading attitude) for both pretest and post-test, with breakdowns by gender and grade level. Second, multivariate analyses were run using both SPSS-PC's MANOVA program (version 6.1), and their new General Linear Model (version 7.0). Multivariate analysis allowed analysis of complex relationships and interactions between the dependent variables (two tests-pretest and post-test, and two reading attitude scores-recreational and academic scores) using a model involving repeated measures with betweensubject factors, and within-subject factors. The General Linear Model procedure was run as a more powerful tool which "can fit repeated measures of within-subject models including doubly multivariate repeated measures models involving multiple measures at each time point or under each combination of conditions." (SPSS, p. 1) These procedures were designed to replace the MANOVA procedure and handle a variety of "messy data situations." (SPSS, p. 2)

A full factorial analysis was completed; then a Stepdown procedure eliminated nonsignificant factors and interactions when possible until the most simple model with all significant interactions was found. If the dependent variables are ordered, it is possible to test for group differences of variables adjusting for effects of other variables using this Stepdown procedure.

The same procedures were used to analyze both the elementary and middle schools separately, though the values changed for each group dependent on the number of schools and the number of grade levels. For example, for the middle schools, the variables included nine schools, two sexes, three grades, two READ scores, and two TEST scores. In the elementary schools, the variables included 17 schools, two sexes, two grades, two READ scores, and two TEST scores. In both 
elementary and middle schools, between-subject factors include schools, grades, and sex while withinsubject factors include TEST and READ which are both repeated measures.

\section{ANALYSIS AND FINDINGS ${ }^{1}$}

\section{Elementary School Respondents}

The elementary school sample included 901 respondents from 17 elementary schools. The number of respondents from each school varied from a low of 22 to a high of 117 . There were 460 male and 441 female students in the respondent group including 673 in the fourth/fifth-grade group and only 228 in the fifth/sixth-grade group. In all the data analysis and graphs, students are identified by their pretest grade; it is important to recognize that each respondent completed a post-test a full academic year later. For example, fourth graders took the pretest and are then identified as the fourth-grade group in both the pretest score and the post-test score (which is completed as they end the fifth grade).

The complete set of mean scores (for both pretest and post-test) for all elementary school respondents is presented in Tables $1 \mathrm{~A}$ and $2 \mathrm{~A}$, with breakdowns by recreational attitudes, academic/school attitudes, and the full reading attitude score. A breakdown is shown by gender (males and females) in Table 1A, and by grade level (grades four and five) in Table 2A. It is interesting to note the high standard deviation scores indicating a wide range of student responses.

Overall male attitudes toward reading are similar for both recreational and school reading while females are considerably more positive toward recreational reading (Table 1A). There were no differences between the scores of fourth graders and fifth graders at the time of the pretest: total mean scores of 59 were found for both fourth and fifth graders (Table 2A). The subscores for recreational and academic reading attitudes were similar by grade level with recreational scores about 2 points higher than those for academic reading. Post-test mean scores show a minor decline on all three scores.

\section{Attitudes toward recreational reading.}

Tables $3 \mathrm{~A}$ and $4 \mathrm{~A}$ display the results of the recreational reading attitude subscale compared first, by gender; then, by grade level. Though females are more positive (32 on pretest, 30 on posttest) toward recreational reading than males (29 and 26 respectively), the decline in score between pretest and post-test is similar (between two and three points) (Table 3A). Both fourth and fifth-grade pretest scores are similar on recreational reading attitudes (30 and 31 respectively); however, the fifth graders' post-test scores go down more as they complete sixth grade (a drop of nearly four, down to 27) as compared to the fourth graders who only drop two points to 28 as they complete fifth grade (Table 4A).

\section{Attitudes toward academic/school reading.}

Tables 5A and 6A display the pretest and post-test scores of students toward academic/school reading, again comparing these scores by gender and grade level. Females are slightly more positive than males (30 compared to 28) at the pretest level; their post-test scores show an equivalent drop of approximately 3 points (Table 5A). Comparing fourth and fifth graders, it can be seen that pretest scores are similar (29 compared to 28) but fifth graders show a somewhat greater decline in scores by the end of sixth grade (a drop of three points) as compared to the fourth graders at the end of fifth grade (a drop of two points) (Table 6A).

\section{Full reading attitude scores.}

Tables 7A and 8A show the total reading attitude scores also compared by gender and grade level. Examining the pretest scores by gender, it can be seen that females feel considerably more positive toward reading; the total mean score for females was 62 as compared to 56 for males (a difference of six points). The drop in both male and female post-tests is similar (about five points), so females end with still more positive attitudes (Table 7A). Comparing fourth graders as they complete fifth grade and fifth graders as they complete sixth grade, there are almost identical pretest scores, but

\footnotetext{
${ }^{1}$ For clarity, all decimals within the text have been rounded to the nearest whole number.
} 
the latter group's post-test scores are seven points lower compared to the fourth/fifth-grade group's decline of only 4 four (Table 8A).

It is important to note that all of these scores are positive, above the midpoint of the scale, rather than either at the low end or at the middle level (which would signify some indifference toward reading). Though the scores did not increase overall at the end of the REAP project, it is important to consider why this might have occurred. There was a difference in the time of the year: pretest at the beginning of the school year, post-test at the end of the second school year. There was no control of differences between the two year time period; intervening variables of different teachers and different classroom reading activities would have occurred. Previous research has shown a considerable decline of reading attitudes as students proceed through the grades at the elementary level, with the most positive attitudes at the first grade level. The scores would probably have declined more without the emphasis on reading brought to the schools through the REAP project. Other studies which have tried to analyze the "effect" of whole language instruction have also found decreases in reading attitudes over grade levels. This study is the only one, to date, that uses the ERAS instrument as part of a twoyear, longitudinal study.

\section{Multivariate Analysis}

Results of the multivariate analysis of variance, using the Stepdown procedure, for the elementary school respondents are displayed in Table 9A which shows several significant $\mathrm{F}$ test results. Full information ( $\mathrm{F}$ scores, the two degrees of freedom, and the significance levels) is presented in the Table and only significance levels will be repeated with the discussion. All results with a $\mathrm{p}$-value of less than $.05(\mathrm{p}<.05)$ were considered significant in the analysis.

The highest level of interactions indicates that school is the most significant factor in explaining differences in respondents; this is evident in the following list of significant interactions:

School x READ x TEST

Grade $x$ School x TEST

Gender x School x TEST

School $x$ TEST

School x READ $(\mathrm{p}<.0001)$

$(\mathrm{p}<.0001)$

$(\mathrm{p}<.026)$

$(\mathrm{p}<.0001)$

$(\mathrm{p}<.0001)$

This means that there were more differences in student attitudes explained by the school of respondents than by their grade, gender, differences in the TEST variable (pretest, post-test), or the differences in READ scores (recreational, academic subscales).

There were significant between-respondents main effects by gender $(p<.0001)$, by grade $(\mathrm{p}<.003)$, and by school $(\mathrm{p}<.0001)$. Also significant within-respondents main effects were found for both the READ variable (recreational, academic subscales) $(\mathrm{p}<.0001)$, and for the TEST variable (pretest, post-test) $(\mathrm{p}<.0001)$.

Other significant interactions not involving school included:
Gender x READ
$(\mathrm{p}<.0001)$

Grade $x$ TEST

$(\mathrm{p}<.012)$

Though there is a significant interaction between gender and READ, there is not such an interaction between gender and grade level. Grade level does interact significantly with TEST ( $\mathrm{p}<.012)$ meaning there are significant differences across grade levels on test scores. It is important to note that 12 of the 17 elementary schools responding only had fourth-grade pretests and this same group took the posttest in fifth grade, so grade level was not a variable in those schools.

Further tests using the Estimated Marginal Means, a GLM procedure, explain the details of the significant factors found in the multivariate analysis. For example, for elementary school respondents, females generally have more positive attitudes toward reading. They also have more positive attitudes toward recreational reading than academic/school reading. The fourth/fifth-grade group is more positive toward reading than the fifth/sixth-grade group. The respondents' pretest scores are higher than their post-test scores, but this varies by grade level. For example, there is only a slight drop between the pretest and post-test of the fourth/fifth-grade group but a greater drop in the scores of the fifth/sixth-grade group. Recreational reading attitude scores are higher than academic/school reading attitude scores. Scores of both the TEST variable and the READ variable differ a great deal in the different schools. For example, in one of the case study schools, male pretest scores are the highest of all schools; even at the post-test level, that score is the fourth highest mean 


\section{$\Delta$}

score. In that same school female pretest scores are the second highest score of all the elementary schools, and at the post-test level, their score is the fifth highest mean score (out of 17 schools). For a second case study school, the fifth/sixth-grade group has the highest pretest and post-test scores, a very unusual pattern.

Table 9A-2 is a table of the significant interactions for each of the 17 elementary schools in order to ascertain any unique differences in schools. This would be most useful to individual schools. 

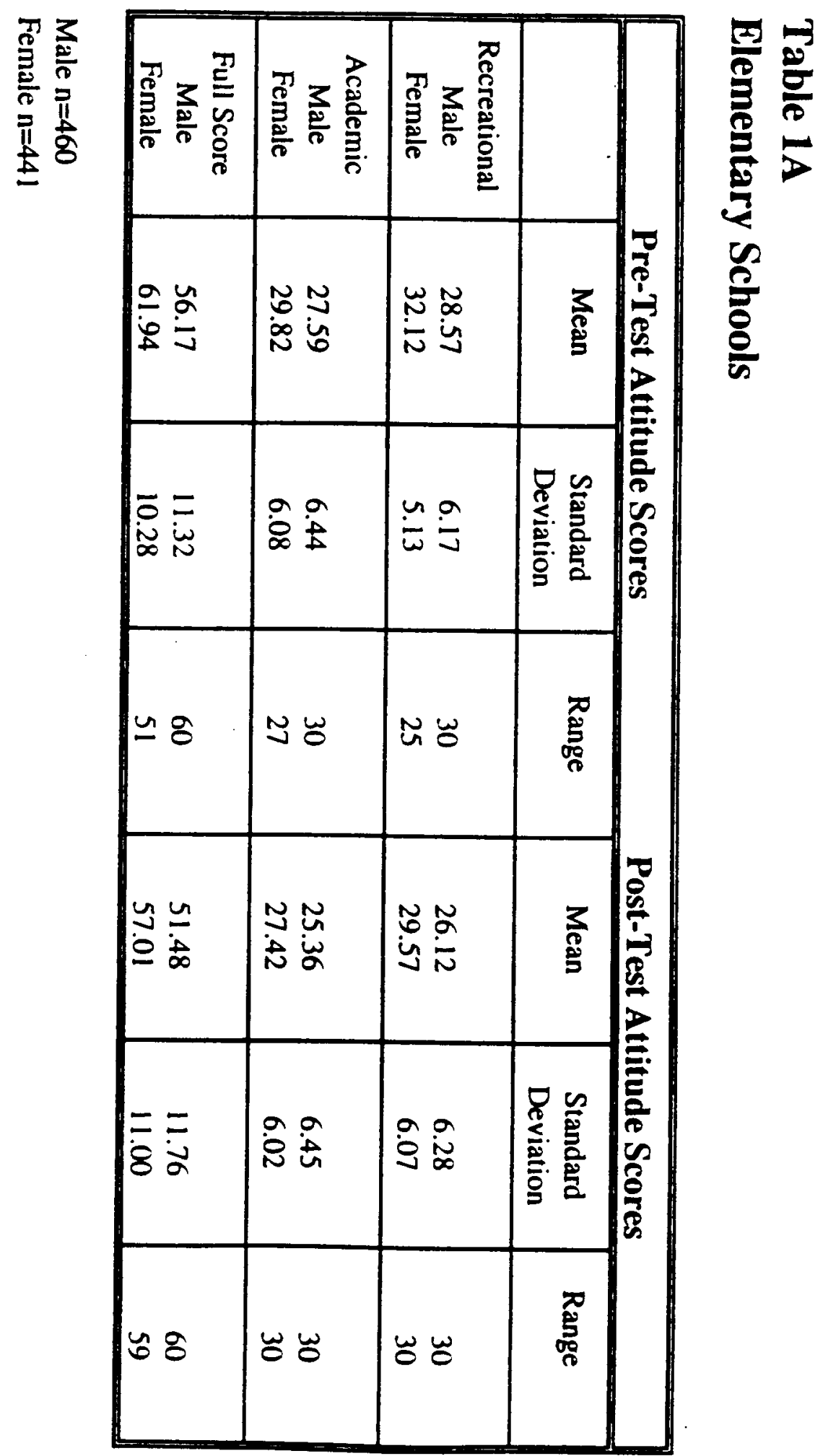

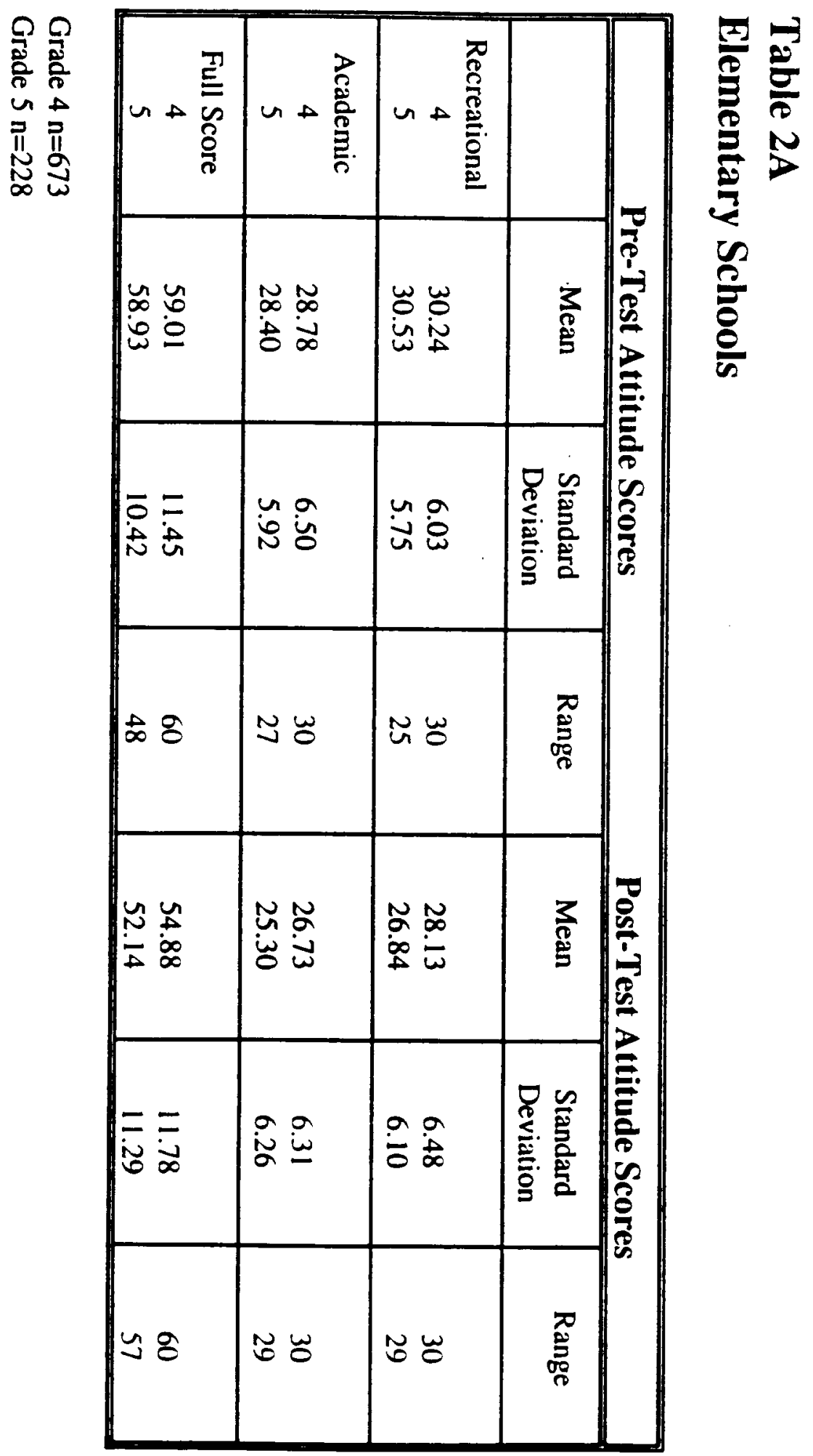


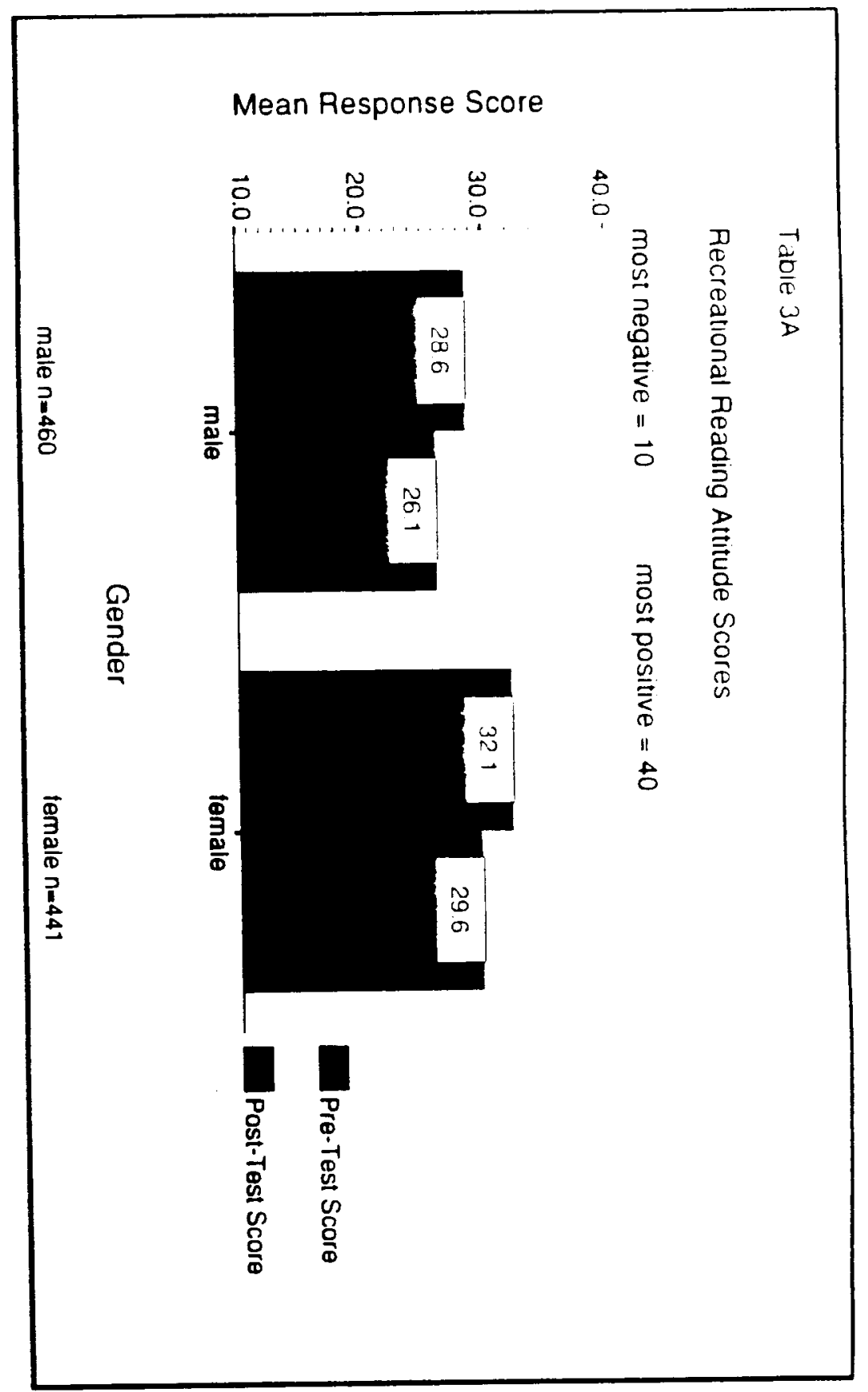




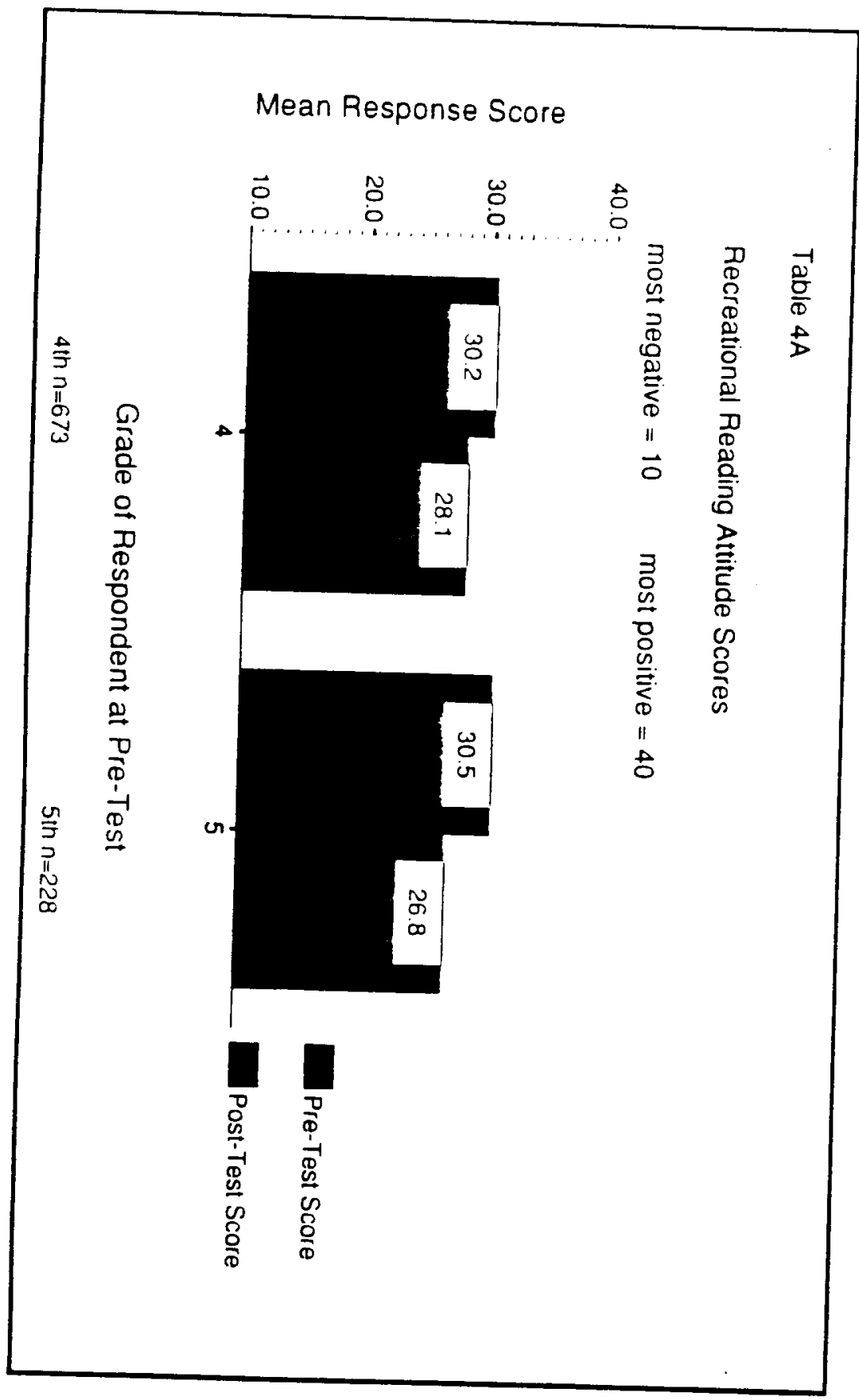




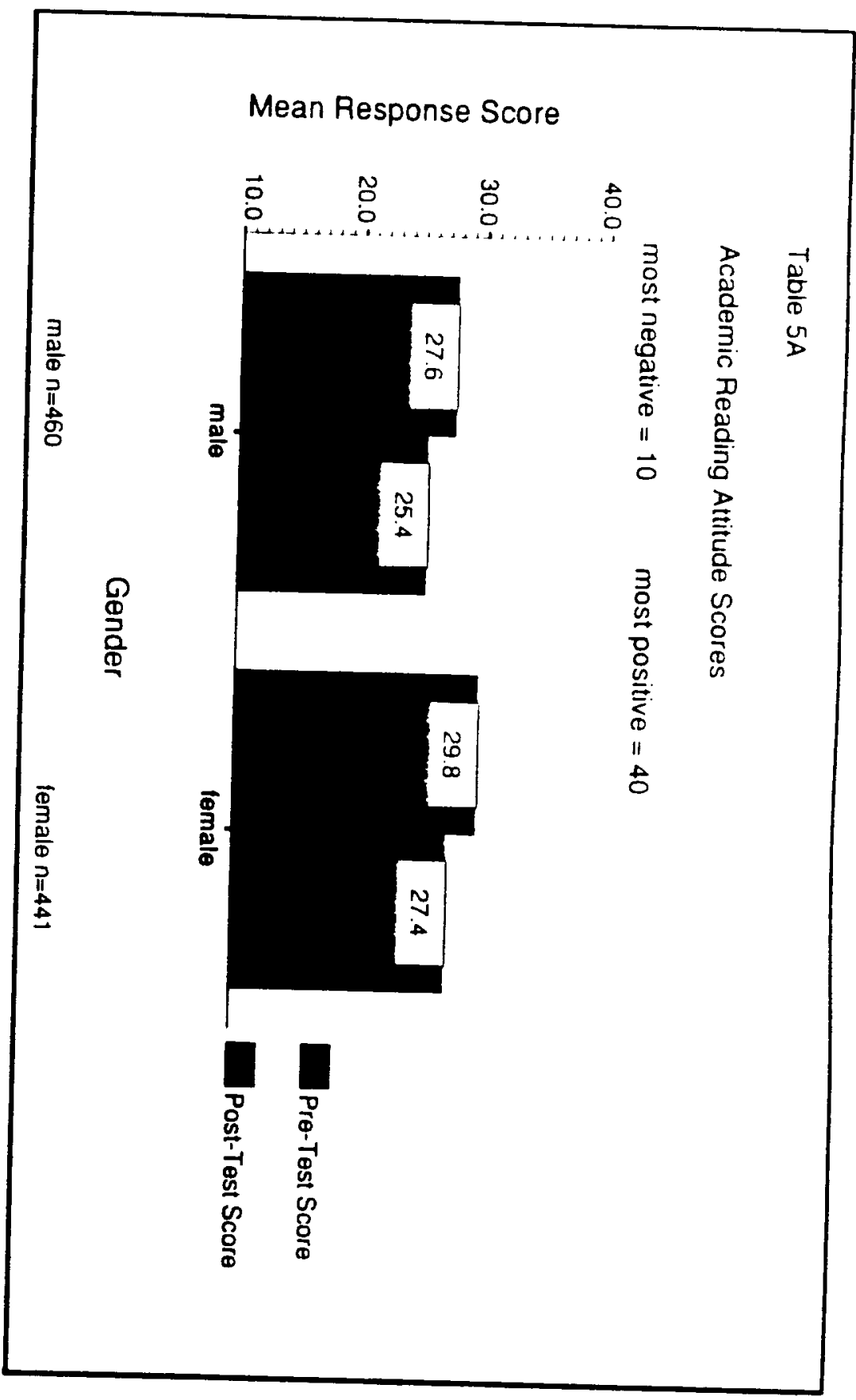




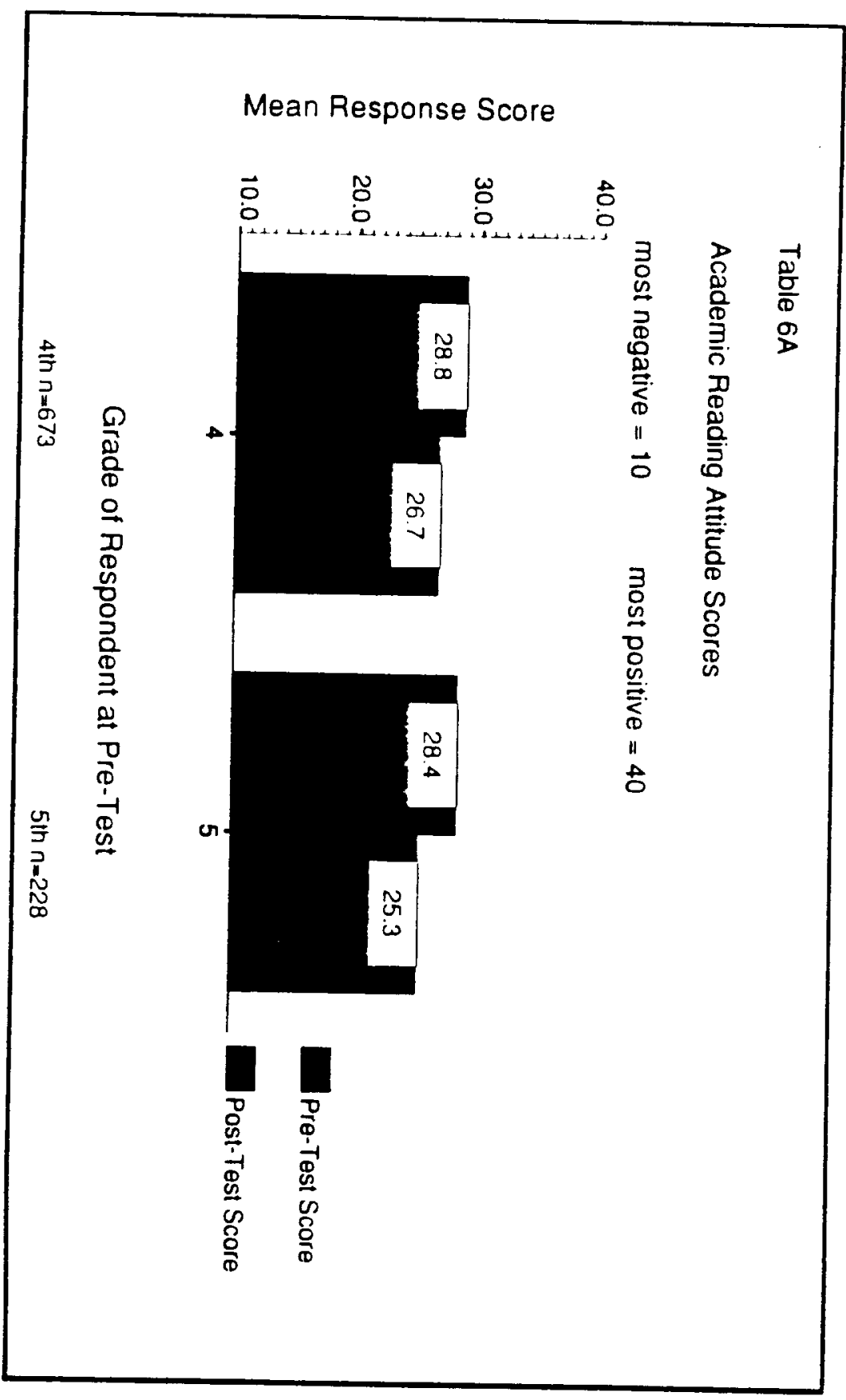




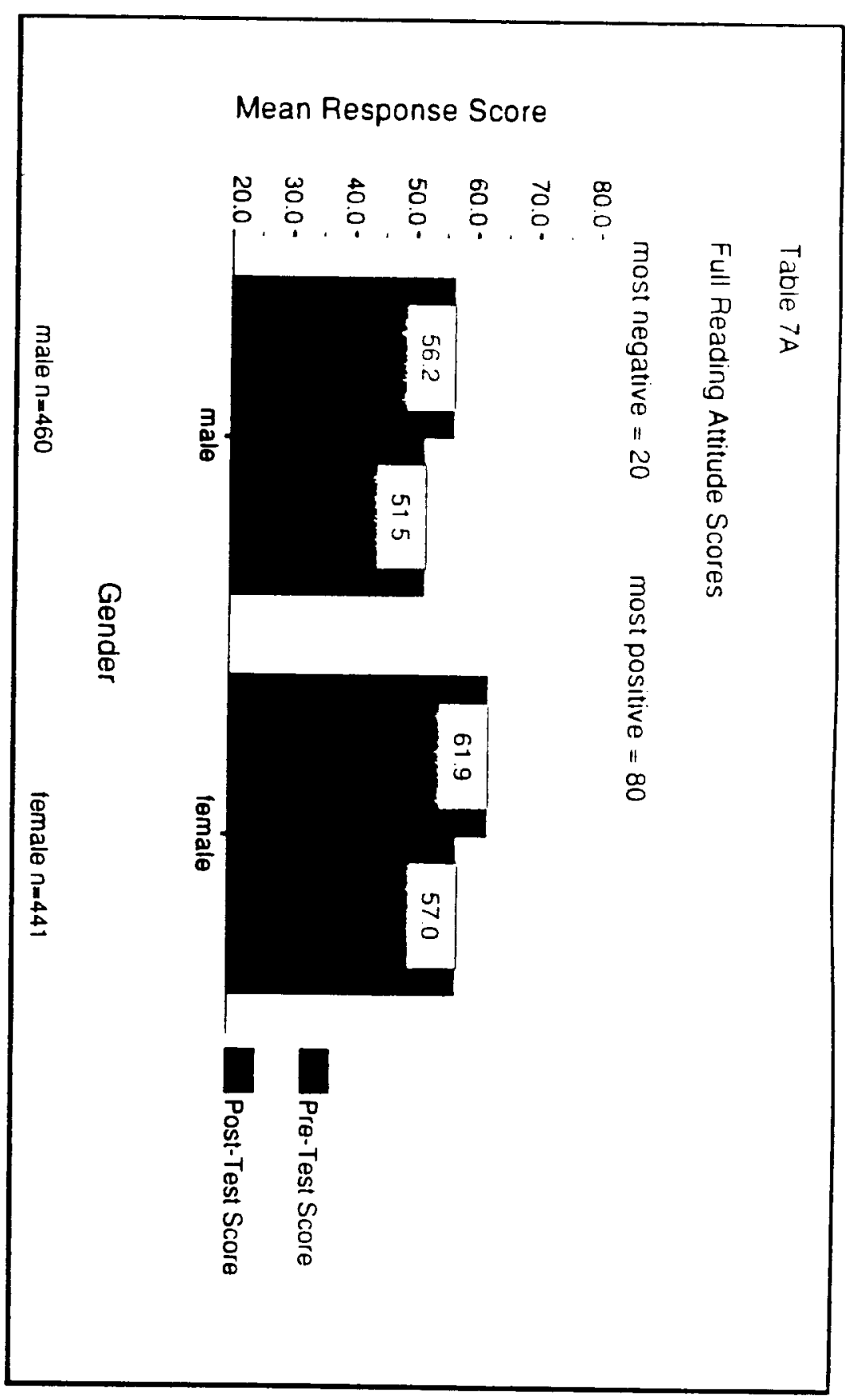




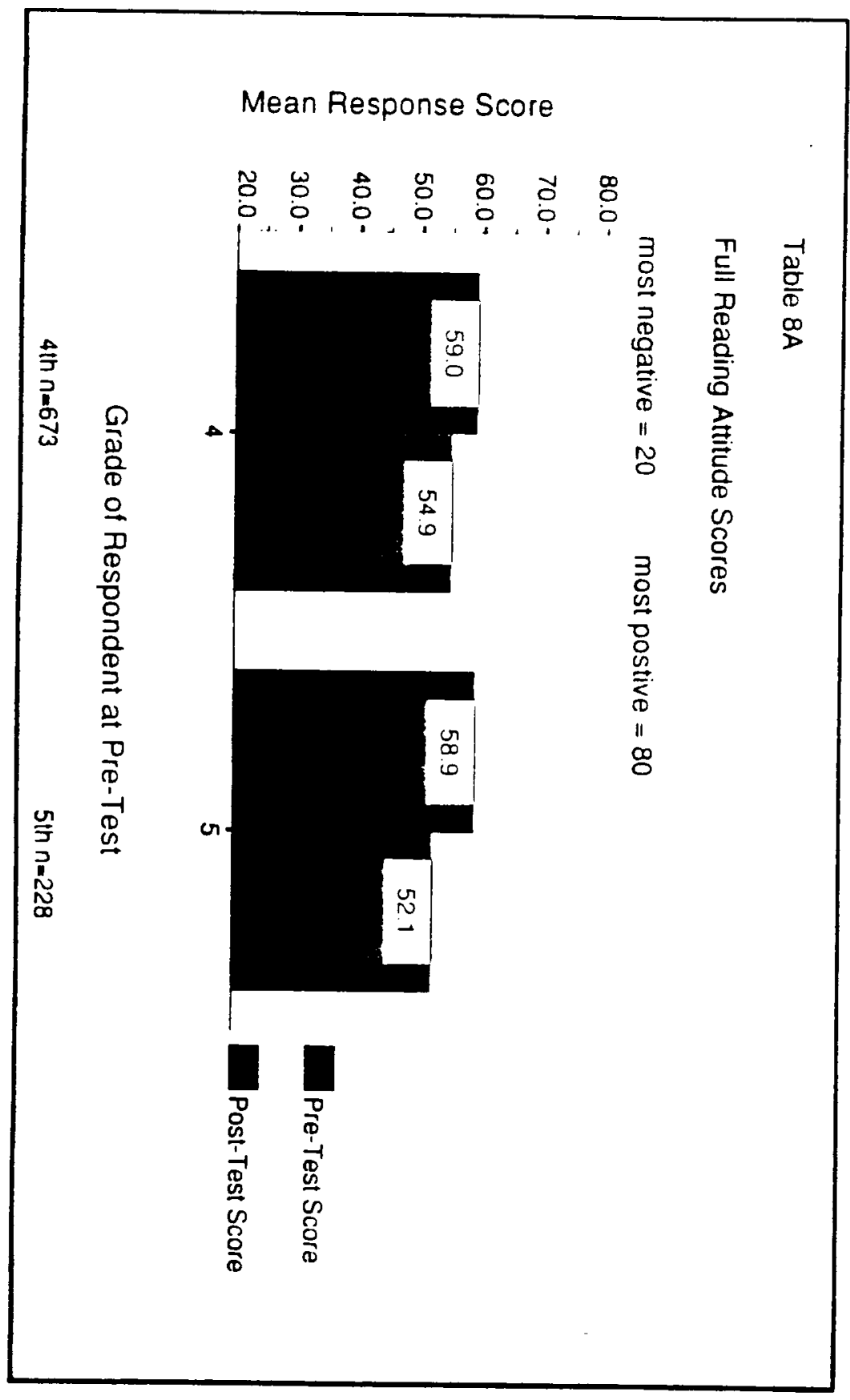




\section{Table 9A-1}

\section{Elementary Schools}

\begin{tabular}{|l|c|c|c|}
\hline \multicolumn{3}{|c|}{ Summary of Step Down Mutivariate Analysis of Variance } \\
\hline Summary & df & F & Significance \\
\hline Gender & $(1,862)$ & 62.71 & .0001 \\
\hline Grade & $(1,862)$ & 8.71 & .003 \\
\hline School & $(16,862)$ & 6.66 & .0001 \\
\hline Gender by School & $(16,862)$ & .44 & .971 \\
\hline Grade by School & $(4,862)$ & 3.66 & .006 \\
\hline READ* & $(1,862)$ & 76.81 & .0001 \\
\hline Gender by READ & $(1,862)$ & 32.32 & .0001 \\
\hline Grade by READ & $(1,862)$ & .41 & .523 \\
\hline School by READ & $(16,862)$ & 6.10 & .0001 \\
\hline Gender by School by READ & $(4,862)$ & 1.38 & .146 \\
\hline Grade by School by READ & $(4,862)$ & .89 & .470 \\
\hline TEST** & $(1,862)$ & 124.32 & .0001 \\
\hline Gender by TEST & $(1,862)$ & .53 & .469 \\
\hline Grade by TEST & $(1,862)$ & 6.30 & .012 \\
\hline Scbool by TEST & $(16,862)$ & 2.90 & .0001 \\
\hline Geader by School by TEST & $(16,862)$ & 1.81 & .026 \\
\hline Grade by School by TEST & $(4,862)$ & 5.07 & .0001 \\
\hline READ by TEST & $(1,862)$ & 1.42 & .234 \\
\hline Gender by READ by TEST & $(1,862)$ & 1.73 & .189 \\
\hline Grade by READ by TEST & $(1,862)$ & 2.30 & .129 \\
\hline Scbool by READ by TEST & $(16,862)$ & 2.63 & .0001 \\
\hline $\begin{array}{l}\text { Gender by School by TEST } \\
\text { by READ }\end{array}$ & $(16,862)$ & 1.44 & .116 \\
\hline Grade by School by TEST \\
by READ & $(4,862)$ & 1.25 & .288 \\
\hline
\end{tabular}

The other interactions were found to be not significant and were not run as part of the Step Down MANOVA.

*READ is the factor composed of the recreational and academic reading attitude scores.

**TEST is the factor composed of the pretest and post-test scores.

Significance level is $p<.05$ 


\section{Table 9A-2}

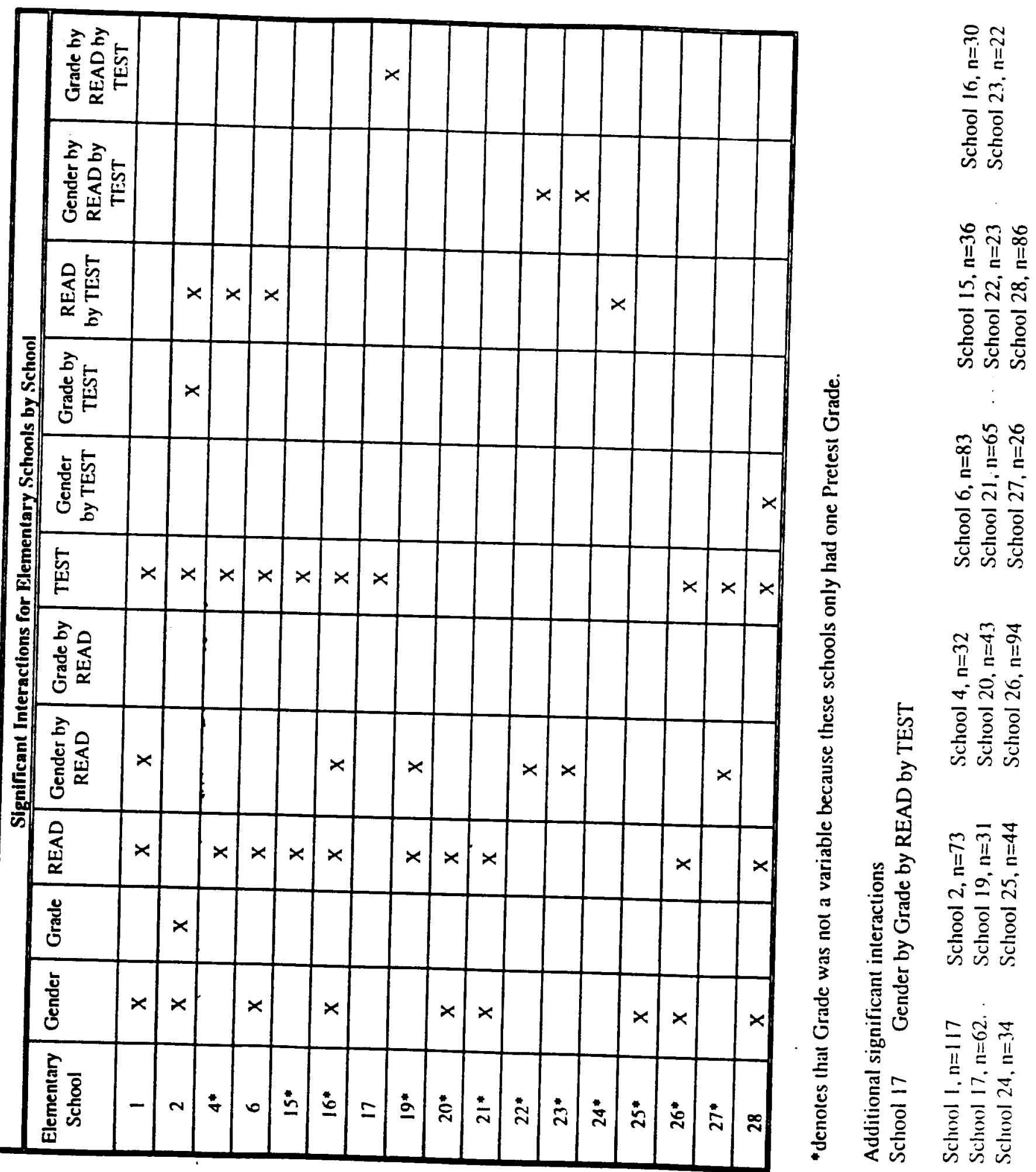




\section{Middle School Respondents}

There were ten middle schools participating in the student attitude study. One school was eliminated from the study because there were only 40 respondents compared to the other middle schools with responses being received from a low of 78 to a high of 253 respondents per school. A total of 1509 responses were available for analysis, including 687 males and 822 females at each of the following grade levels:

$\begin{array}{ll}\text { Grade five/six } & 180 \\ \text { Grade six/seven } & 443 \\ \text { Grade seven/eight } & 886\end{array}$

These numbers show that few of the middle schools had fifth grades and most had only seventh and eighth grades. It is important to recognize that the fifth-grade pretest is matched with those same students' post-test as they completed sixth grade; sixth-grade pretest with seventh-grade post-test, and seventh-grade pretest with eighth-grade post-test. In the following data analysis and charts, students will be identified by their pretest grade only. Some rounding of scores is done in the discussion of results for the purpose of clarity.

Tables $1 \mathrm{~B}$ and $2 \mathrm{~B}$ present the mean scores for all the middle school respondents, comparing pretest and post-test scores for recreational and academic subscores as well as the full reading attitude scores, for both males and females (gender) and by grade levels. These means ranged from a low of 21 to a high of 30. As in the elementary school respondents, there is a wide range of responses, indicated by the high standard deviation scores. In reference to the scale depictions of Garfield, this ranges from below the midpoint—close to the slightly frowning Garfield — to near the slightly smiling Garfield. Thus, the subgroup means varied from a somewhat negative attitude to a somewhat positive attitude. Females were more favorable toward recreational reading than academic reading while males felt about the same toward both. Scores were lower at each higher grade level.

More specifically, in Table 1B, male scores are over four points lower than female scores on the recreational pretest but only two points lower on the academic/school pretest, for a difference on the full reading attitude score of over six points. Post-test scores decline similarly between males and females with females still having more positive attitudes at the end of the second academic year.

In Table 2B, full scores of reading attitudes of middle school students varied by grade level at the time of the pretest: the mean pretest response of fifth graders' full score was 59; sixth graders, 56; and seventh graders, 52. This follows the general pattern found in previous research: that students have a less positive attitude toward reading as they progress through the grades. If you look at the two subscales at the pretest level, they show that attitudes toward recreational reading are only slightly more positive than academic/school reading: grade five (30 compared to 29), grade six (28), and grade seven (27 compared to 25 ).

At the middle school level, full scores were lower on the post-test for each grade level, but the largest drop was evident for the sixth graders who began with an overall mean pretest score of 56 and by the end of the second academic year, as seventh graders, their mean post-test score dropped to 47, a nine point drop. At the fifth/sixth-grade level the drop was seven (from 59 to 52); at the seventh/eighth-grade level, the drop was eight (52 to 44). There were minor differences in the rate of decrease between pretest and post-test scores on recreational and academic attitudes. For recreational scores, the fifth grades dropped from 30 to 27 (three points) and for academic scores, 29 to 25 (four points). Sixth graders had almost identical pretest scores on the two: 28 on both recreational and academic; these scores dropped to 24 and 23 respectively, the same rate of decrease in both and almost identical scores at both pretest and post-test levels. For seventh graders, the scores began at 27 (recreational) and 25 (academic) and dropped to 23 (recreational) and 22 (academic), drops of approximately four and three respectively.

\section{Attitudes Toward Recreational Reading}

Tables 3B and 4B display the results of the recreational reading attitude subscale, compared by gender and then by grade level. At the pretest level, females score approximately five points higher than males (30 compared to 25) and at the post-test level, the difference is similar (four points, 25 compared to 21) (Table 3B). Comparing grade level differences on the recreational scale, there is a gradual decrease between the pretests of fifth, sixth, and seventh graders $(30,29$, and 27$)$ and a more substantial drop on the post-tests $(27,24,23$ respectively) (Table 4B). 


\section{Attitudes toward Academic/School Reading}

Comparing Table $5 \mathrm{~B}$ with Table $3 \mathrm{~B}$, it is evident that males have identical attitudes toward academic/school and recreational reading (25) with a similar decrease on the post-test (four points). Females are somewhat more positive toward recreational (30) than academic/school reading (27) and show a similar decrease in attitude at the post-test level (four points). Looking at grade level differences (Table 6B), academic/school pretest scores begin somewhat lower than recreational scores, especially at the seventh-grade level, and decline more at the post-test level, except at the seventh/eighth-grade level where there is less of a decline on academic/school post-tests. The group moving from sixth grade to the end of seventh grade has a greater decline (five) in academic/school post-test score than the other groups, compared to a decrease of four between fifth/sixth graders, and nearly four between seventh/eighth graders. All academic/school reading post-tests are below the midpoint of the scale (25) and indicate some indifference to academic/school reading.

\section{Full Reading Attitude Scores}

Females are substantially more positive than males, seen in Table 7B, on their pretest reading attitude scores (57 compared to 51); the rate of decline in post-test attitude is slightly higher for females (nine points as compared to eight for males). Most of this difference between males and females was on the recreational scores, with females more positive than males by four points. Scores on the academic/school subscale were more similar between males and females. Though girls were initially more positive on both attitude subscales than boys, their drop in score was approximately the same or slightly greater than that of the boys.

Comparing grade level differences in Table $8 \mathrm{~B}$, though there is a steady decrease by grade level on pretest scores $(59,56$, and 52), there is an uneven rate of decline in attitudes from pretest to post-test scores, with declines of seven for fifth/sixth graders, nine for sixth/seventh graders, and eight for seventh/eighth graders.

To summarize the results of the middle school respondents' reading attitudes, females have more positive attitudes than males, especially on recreational reading. Males do not differ much on their attitudes toward recreational and academic/school reading. Scores between pretest and post-test decline somewhat more for females. For the students at the middle school level, there seems to be a decline in reading attitudes, especially toward academic/school reading among the sixth/seventh graders.

\section{Multivariate Analysis}

Results of the multivariate analysis using the Stepdown procedure for the middle school respondents are displayed in Table 9B which shows several significant $\mathrm{F}$ test results. Full information ( $\mathrm{F}$ scores, the two degrees of freedom, and the significance levels) is presented in the Table and only significance levels are mentioned in the discussion. All results with a p-value of less than $.05(\mathrm{p}<.05)$ were considered significant in the analysis.

At the highest level of interactions, school is the most significant factor that explains differences in respondents, as shown in the following list of significant interactions:

$\begin{array}{ll}\text { School x Gender } & (\mathrm{p}<.03) \\ \text { School x READ } & (\mathrm{p}<.0001) \\ \text { School x TEST } & (\mathrm{p}<.0001)\end{array}$

This means that there were more differences in student attitudes explained by the school of respondents than by their grade level, gender, differences in TEST (pretest, post-test) or the differences in READ scores (recreational, academic/school subscales).

Besides this second order of interactions, the only third level of interaction (also including the school variable) which was close to significance was: School x Gender x Read $(\mathrm{p}<.052)$.

Significant between-respondents main effects were found for school $(p<.0001)$ gender $(\mathrm{p}<.0001)$ and for grade level $(\mathrm{p}<.0001)$. Yet the interactions between gender by grade, and between school by grade were not significant. There were also significant within-respondents main effects found for both the READ variable (recreational, academic subscales) $(\mathrm{p}<.0001)$ and for the TEST variable (pretest, post-test) $(\mathrm{p}<.0001)$.

Other significant interactions not involving school included:

Gender x READ

$(\mathrm{p}<.0001)$

Grade $x$ TEST

$(\mathrm{p}<.02)$ 
This means that gender did affect differences on the two subscales of reading attitudes, and grade level did affect differences on the pretest and post-test scores.

Further tests using the Estimated Marginal Means, a GLM procedure, explain the details of the significant factors found in the multivariate analysis. Like the elementary school respondents, females have more positive attitudes toward reading. Male attitudes are the same toward both subscales of reading attitudes (recreational and academic/school), while females show more positive attitudes toward recreational reading. Pretest scores are generally higher than post-test scores for the middle school respondents. At the middle school level, reading attitude scores decline at each grade level, both on the pretest, and with a somewhat greater decline by grade level on the post-test. Recreational reading scores are only slightly higher overall; this is accounted for by male scores which reflect a similar attitude toward both recreational reading and academic/school reading. Schools vary tremendously in their pattern of reading attitude scores. For example, one of the case study middle schools had the second highest pretest score and the highest post-test score, with one of the smallest declines in score.

Table 9B-2 is a table of the significant interactions of each of the nine middle schools to ascertain any unique differences in schools. This would be most useful to individual schools. 

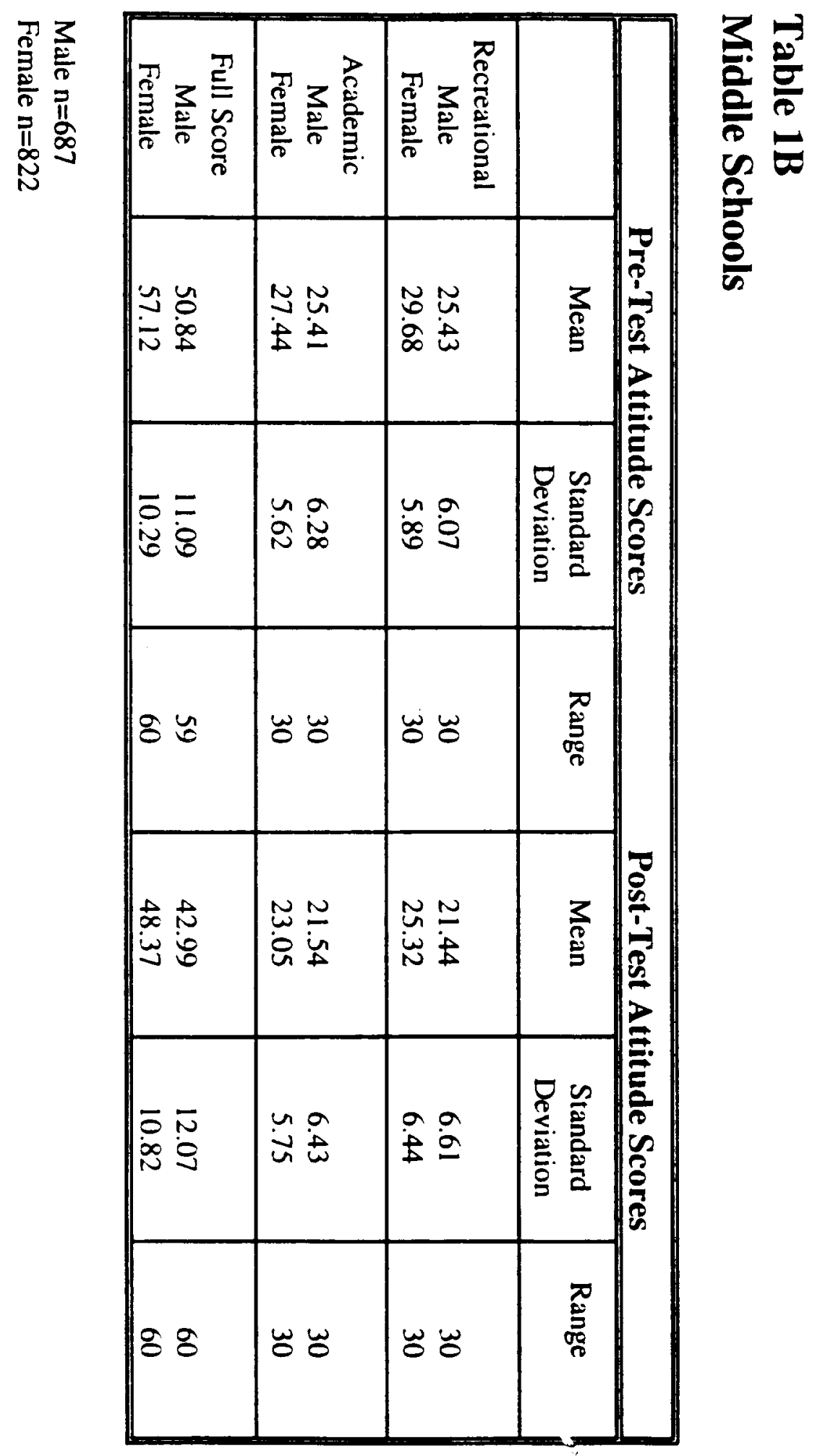


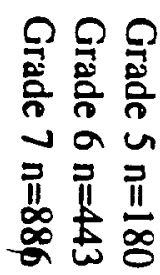

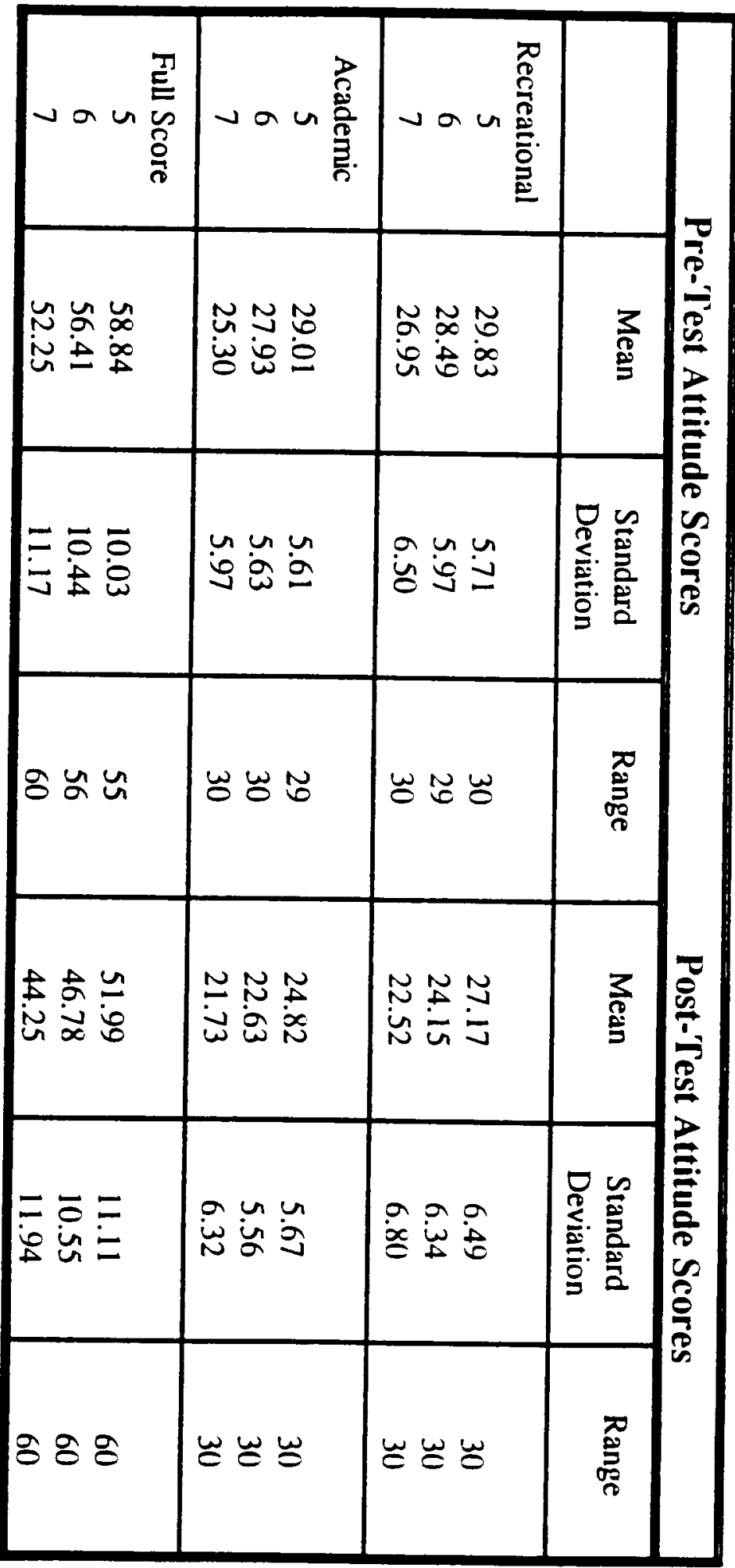


Table 38

Recreational Reading Attitude Scores

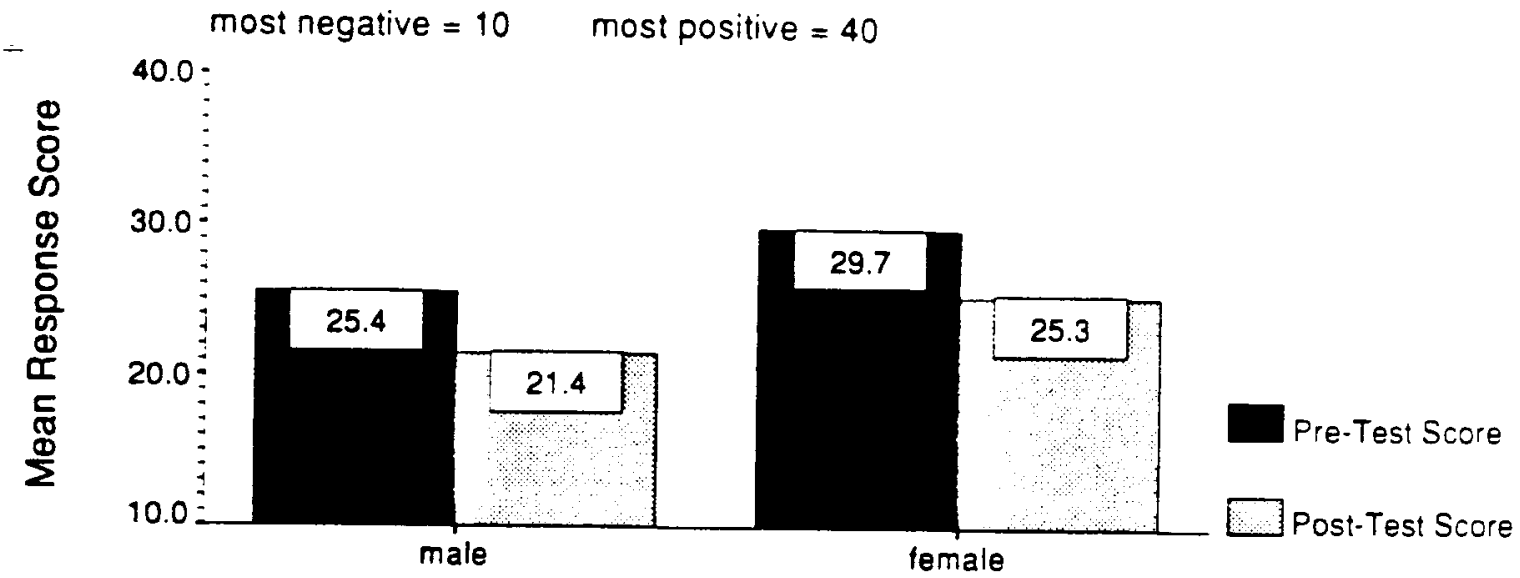

Gender

Table 4B

Recreational Reading Attitude Scores

most negative $=10 \quad$ most positive $=40$

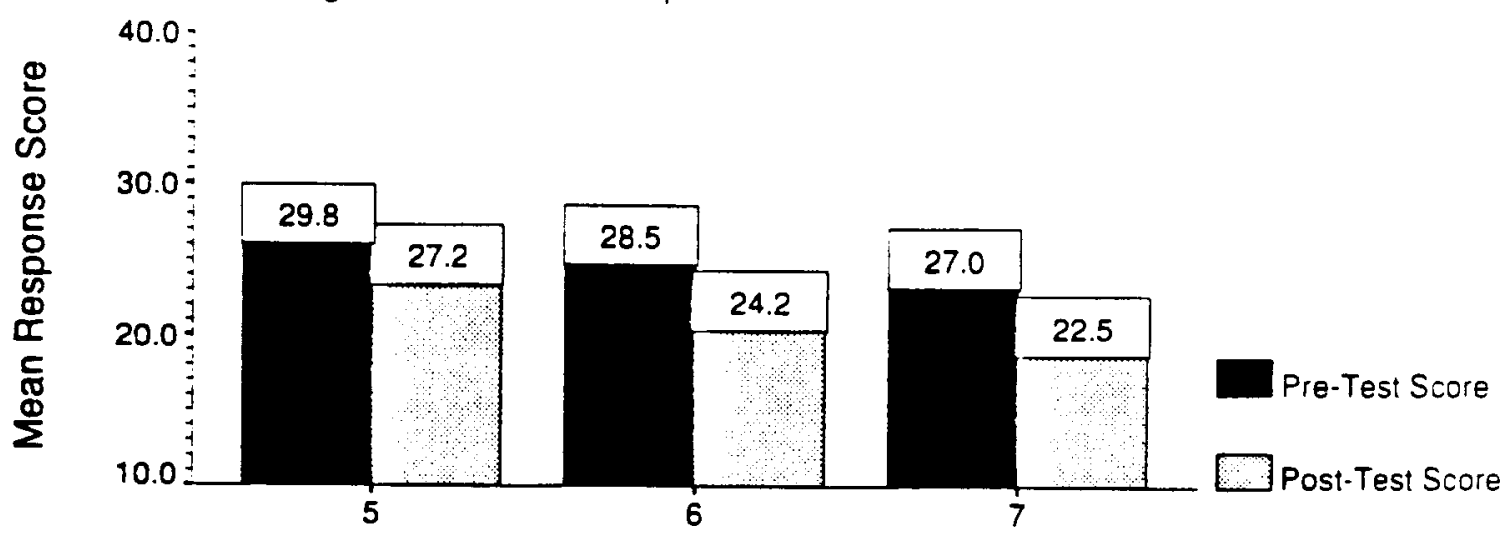

Grade of Respondent at Pre-Test 


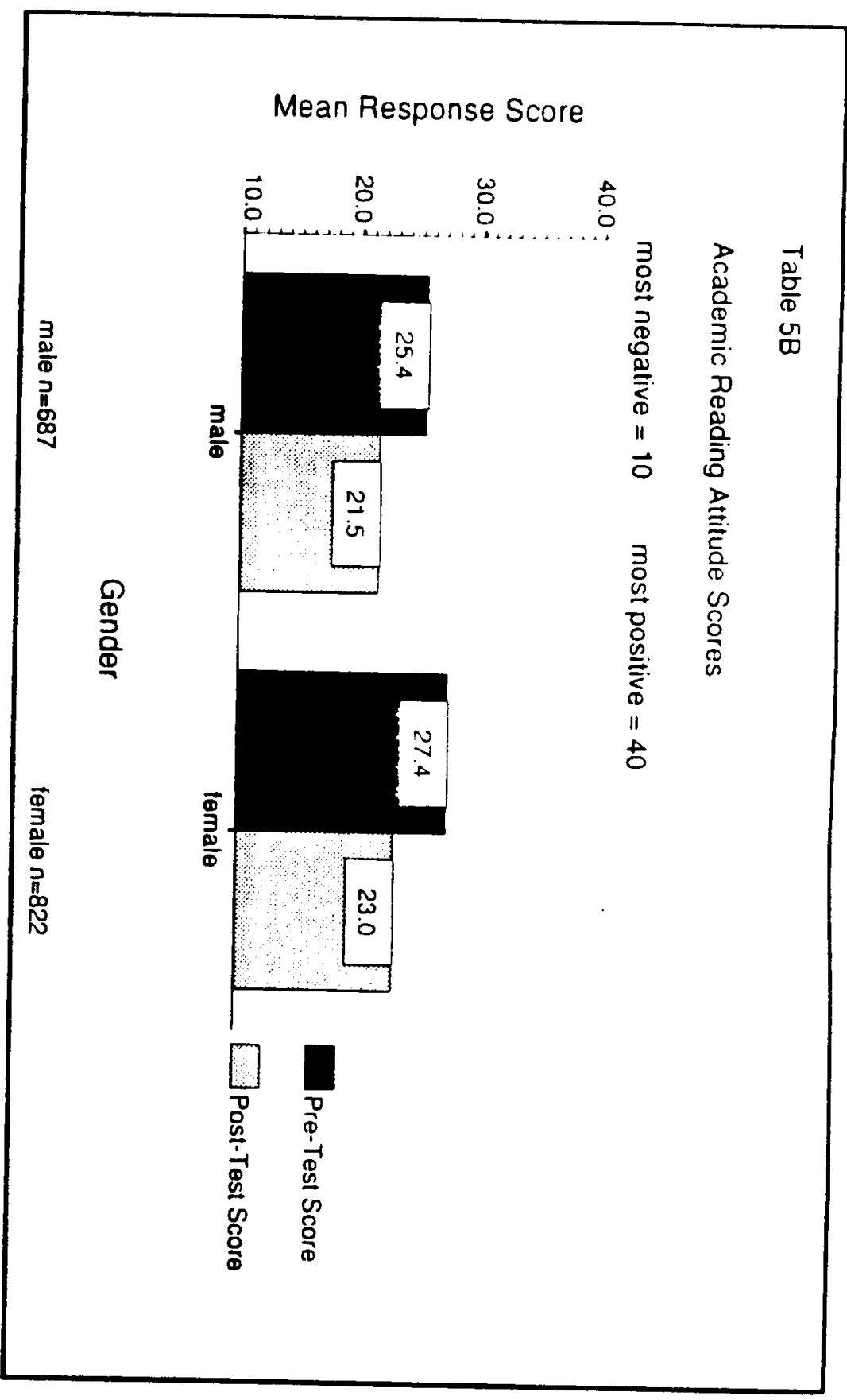




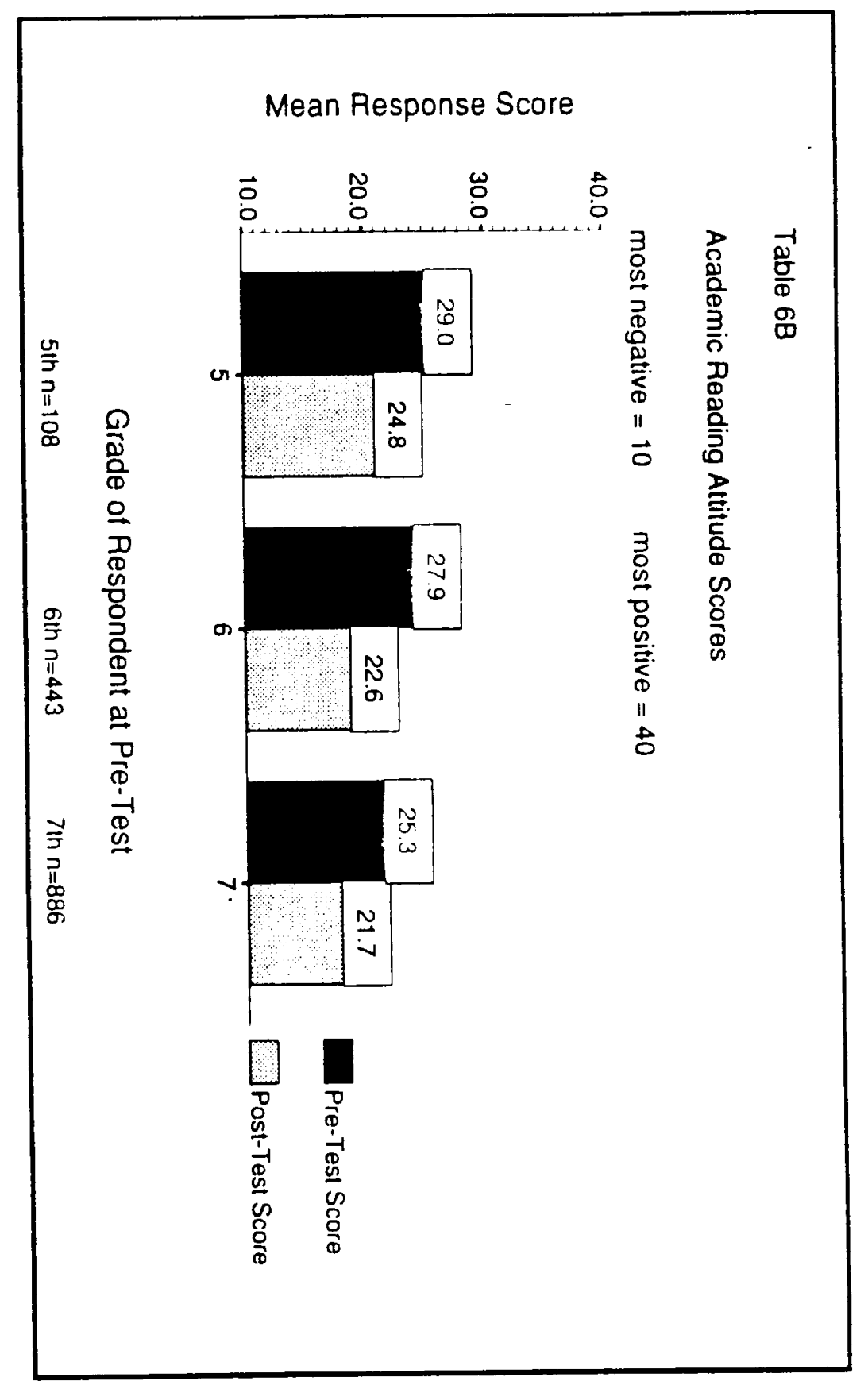




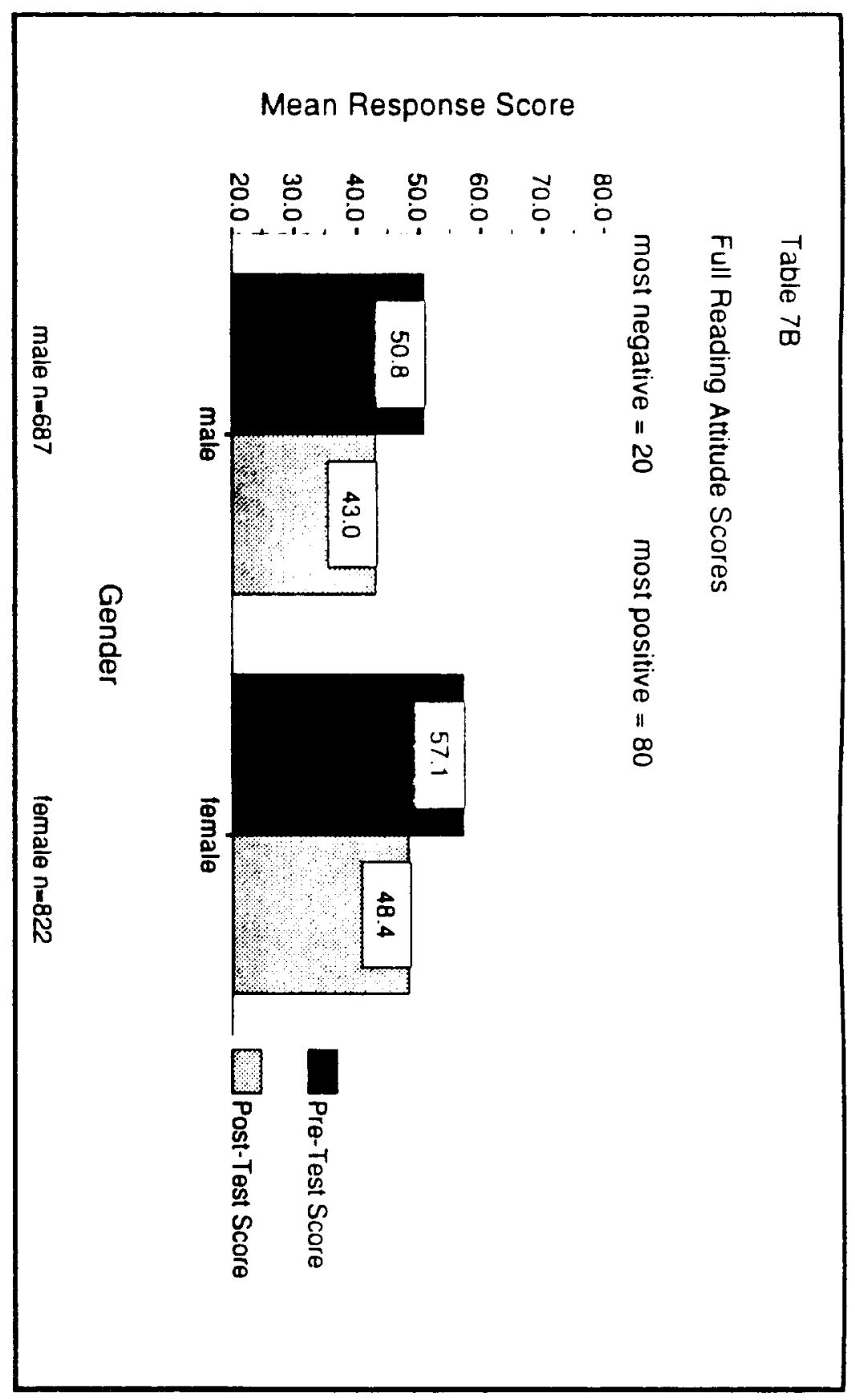




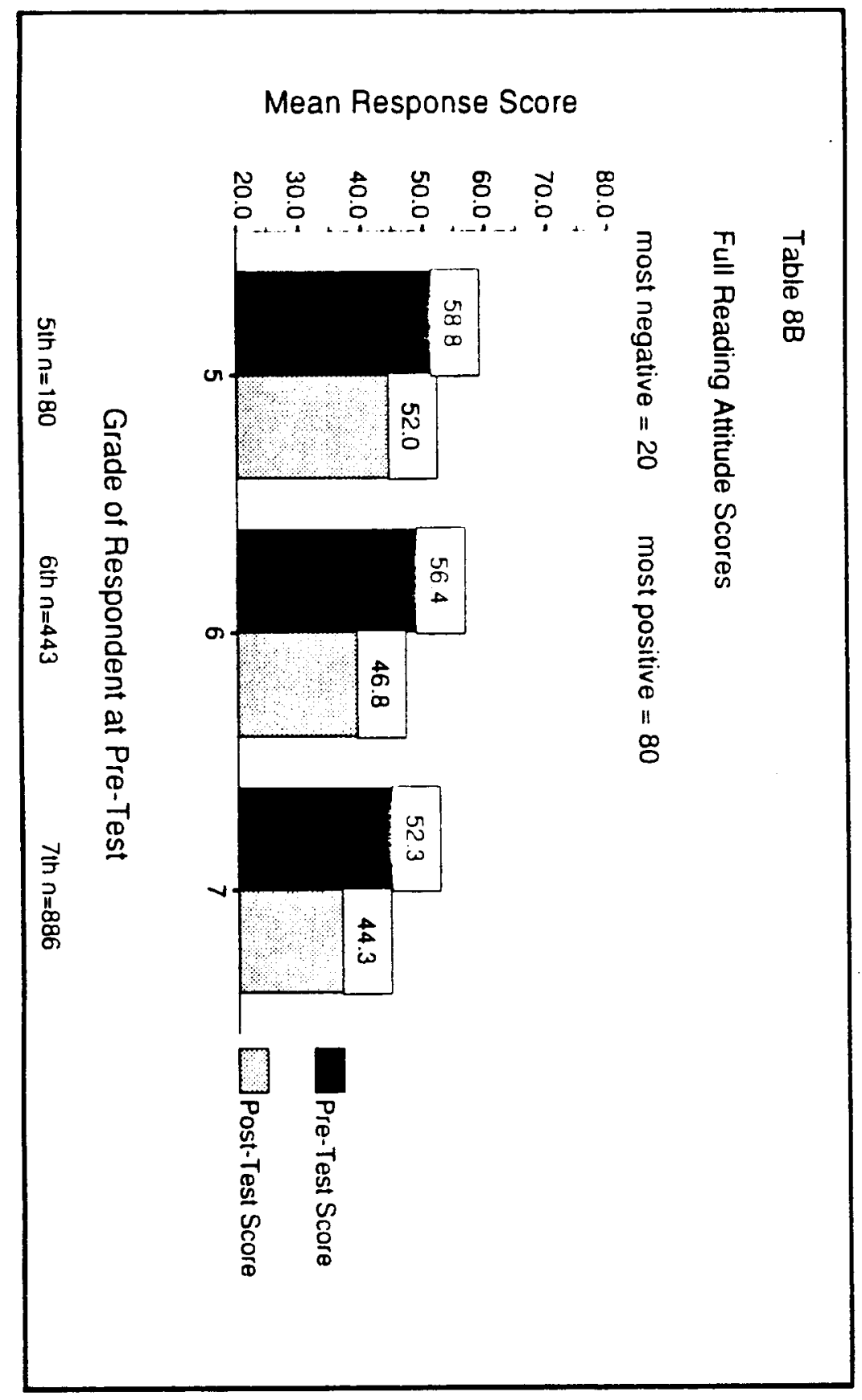




\section{Table 9B-1}

\section{Middle Schools}

\begin{tabular}{||l|c|c|c||}
\hline \multicolumn{3}{|c|}{ Summary of Step Down Mutivariate Analysis of Variance } \\
\hline Summary & $\mathrm{df}$ & $\mathrm{F}$ & Significance \\
\hline Gender & $(1,1489)$ & 136.32 & .0001 \\
\hline Grade & $(2,1489)$ & 41.07 & .0001 \\
\hline School & $(8,1489)$ & 8.50 & .0001 \\
\hline Gender by School & $(8,1489)$ & 2.04 & .039 \\
\hline READ* & $(1,1489)$ & 46.82 & .0001 \\
\hline Gender by READ & $(1,1489)$ & 82.41 & .0001 \\
\hline Grade by READ & $(1,1489)$ & 1.65 & .191 \\
\hline School by READ & $(8,1489)$ & 18.60 & .0001 \\
\hline Gender by School by READ & $(8,1489)$ & 1.93 & .052 \\
\hline TEST** & $(1,1489)$ & 358.22 & .0001 \\
\hline Gender by TEST & $(1,1489)$ & .82 & .367 \\
\hline Grade by TEST & $(2,1489)$ & 3.66 & .026 \\
\hline School by TEST & $(8,1489)$ & 5.64 & .0001 \\
\hline Gender by School by TEST & $(8,1489)$ & .76 & .636 \\
\hline
\end{tabular}

The other interactions were found to be not significant and were not run as part of the Step Down MANOVA.

*READ is the factor composed of the recreational and academic reading attitude scores.

**TEST is the factor composed of the pretest and post-test scores.

Significance level is $\mathrm{p}<.05$ 


\section{Table 9B-2}

\begin{tabular}{|c|c|c|c|c|c|c|c|c||}
\hline \multicolumn{7}{|c|}{ Significant Interactions for Middle Schools by School } \\
\hline $\begin{array}{c}\text { Middle } \\
\text { School }\end{array}$ & Gender & Grade & READ & $\begin{array}{c}\text { Gender by } \\
\text { READ }\end{array}$ & $\begin{array}{c}\text { Grade by } \\
\text { READ }\end{array}$ & TEST & $\begin{array}{c}\text { Gender by } \\
\text { TEST }\end{array}$ & $\begin{array}{c}\text { Grade by } \\
\text { TEST }\end{array}$ \\
\hline 5 & $\mathrm{X}$ & $\mathrm{X}$ & $\mathrm{X}$ & $\mathrm{X}$ & & $\mathrm{X}$ & & \\
\hline $7^{*}$ & $\mathrm{X}$ & & $\mathrm{X}$ & $\mathrm{X}$ & & $\mathrm{X}$ & & \\
\hline 8 & $\mathrm{X}$ & $\mathrm{X}$ & $\mathrm{X}$ & $\mathrm{X}$ & & $\mathrm{X}$ & & $\mathrm{X}$ \\
\hline 9 & $\mathrm{X}$ & $\mathrm{X}$ & $\mathrm{X}$ & $\mathrm{X}$ & & $\mathrm{X}$ & & \\
\hline 10 & $\mathrm{X}$ & & & $\mathrm{X}$ & & $\mathrm{X}$ & & $\mathrm{X}$ \\
\hline $11^{*}$ & & & $\mathrm{X}$ & & & $\mathrm{X}$ & & \\
\hline $12^{*}$ & $\mathrm{X}$ & & $\mathrm{X}$ & & & $\mathrm{X}$ & & \\
\hline $13^{*}$ & $\mathrm{X}$ & & $\mathrm{X}$ & $\mathrm{X}$ & & $\mathrm{X}$ & & \\
\hline 14 & $\mathrm{X}$ & $\mathrm{X}$ & $\mathrm{X}$ & $\mathrm{X}$ & $\mathrm{X}$ & $\mathrm{X}$ & & \\
\hline
\end{tabular}

*denotes that Grade was not a variable because these schools only had one Pretest Grade.

Additional significant interactions

School 7 READ by TEST

School 8 READ by TEST

School 9 Gender by READ by TEST

School 12 READ by TEST

School 13 READ by TEST

School 14 READ by TEST

School $5, n=200 \quad$ School $7, n=159$

School 10, $n=183 \quad$ School $11, n=78$

School 14, $n=162$
School 8, $n=208 \quad$ School 9, $n=253$

School 12, $n=147 \quad$ School 13, $n=119$ 


\section{Limitations of the Study}

The specific questions on the ERAS had been designed and tested for use with grades one through six in elementary schools. The current use of the instrument at the middle school level is an extension of its use without further testing for reliability or validity, and results should be used with caution. It may be that the academic/school questions and resulting subscale are not appropriate for middle school students. The recreational scale appears to be quite suitable for this level. There are no standard scores developed for any grades above the sixth grade.

A potential problem with the current study is that the timing of the pretest and the post-test may make the results less reliable. For example, one principal mentioned that at the middle school level, students' attitudes were most positive at the time when the preview book collections were brought to the school; this was the pretest time in some schools. In addition, the post-tests were administered during the last two months of school before summer vacation when student attitudes might be at their lowest. The combination of more positive attitudes during pretesting and less positive during post-testing may partly account for the general pattern of attitude decline over the two-year time period.

The longitudinal view of students' reading attitudes over a two-year time period is valuable; however, it must be recognized that there are several uncontrolled variables in the study, such as different teacher styles and changes in reading instruction over the time period.

\section{DISCUSSION}

The current study presents general information on student reading attitudes. This study was not able to "prove" that the REAP projects in the schools improved student attitudes toward reading. It should be recognized that in general, these students' attitudes were favorable about reading as most scores were at or above the midpoint level of the Garfield scale. The decline in score may be attributed to the normal decline in interest in reading as students move into higher grade levels, a finding of the most recent research on reading attitudes. The specific scores and the level of decline from the pretest to post-test need to be compared with other studies of those schools employing similar interventions and those without interventions.

At both the elementary school and middle school levels, the difference between schools was the most significant factor in explaining differences in respondents' reading attitudes. At the elementary school level, there were three high level interactions involving school: school by TEST by READ; school by TEST by grade; and school by TEST by gender. At the middle school level, there were no significant interactions at this level of interaction, but school was involved in several two-way interactions: school by gender, school by READ (recreational, academic/school scores), and school by TEST (pretest, post-test scores). Gender was a significant main effect as well at both levels, and it did affect the READ scores (females and males differed in their recreational and academic/school reading attitudes). Gender differences were not significant by grade level at either school level. Grade level was significant by the TEST variable, indicating that pretest and post-test differed by grade level.

In both elementary and middle schools, females had more positive attitudes toward reading; their recreational reading attitudes are more positive than their academic/school reading attitudes. The fourth/fifth-grade group was the most positive group at the elementary school level. A similar pattern was found at the middle school level: the fifth/sixth-grade group had the most positive attitudes, the sixth/seventh group was less positive, and the seventh/eighth-grade group was the least positive. This differs somewhat by school. In both the elementary and middle school groups, the pretest scores are more positive than the post-test scores, yet at the elementary level there is less of a difference though it differs by grade level with the fifth/sixth-grade group's post-test score dropping dramatically.

Though recreational reading attitude scores are more positive than the academic/school attitude scores, the scores differ less at the middle school level; this is accounted for by the pattern for males whose recreational and academic scores are almost identical.

Schools vary tremendously in their pattern of reading attitude scores which suggests that activities at the school, teacher quality, and school environment probably affect these differences. It is important to recognize that the REAP 3 schools were similar in several respects: there were large numbers of at-risk students, and the REAP activities (as interventions) were similar, including the influx of a large number of new, attractive, popular books and the initiation of these activities: Sustained, Silent Reading (SIR), teacher read-alouds, and classroom book collections. 
It would also be useful to compare the findings of this study with the previous use of the ERAS instrument as well as with other studies of attitudes of middle school students. Important comparisons should be made on: grade level differences, gender differences, and introduction of specific reading activities such as SIR, teachers reading aloud, and incentive programs. Other researchers have begun to explore the effect and relationship of "whole language teaching" on student reading attitudes and behaviors. Those studies should be reexamined to compare results with the current findings.

\section{IMPLICATIONS FOR SCHOOLS AND TEACHERS}

The study was invaluable in showing the relationship between attitude testing and actual descriptions of children and teachers about student reading during both written surveys (teachers only) and on-site interviews for five case study reports. The multi-operational aspect of this study was one of the most important aspects of the study: that is, the verification of the same information via a written, standardized attitudinal instrument compared with the actual words of students describing how they felt about reading (at home, at school, with friends); and the comparison of teachers' written surveys with their face-to-face descriptions of how they felt student attitudes and behaviors had changed. For this presentation, it is essential to show that students described themselves as "liking reading" and spending quite a bit of time reading at home, except for summer vacations. Teachers felt that having greater access to books in school libraries and in classroom libraries, as well as letting students help choose these special books, was the primary benefit of the project. Almost all of them felt that students' attitudes toward reading had become more positive, and that students were reading more now that more classroom time was spent on reading activities.

The attitudinal part of the survey was valuable in itself in the differences it elicited between grade levels, between genders, and especially between schools. Though the researcher needs to spend more time trying to theorize from the multiple data sources and to posit generalizations which need to be retested, there are some indicators in the findings that can be useful immediately. For example, male students seem to feel the same toward school and recreational (home) reading; this seems to indicate that more time is needed in school for what one usually labels "recreational reading." Some of the specific attitudinal questions (especially in the recreational reading section) elicited results which need further consideration. Two questions illustrate this point most effectively:

How do you feel about reading during summer vacation?

How do you feel about going to a bookstore?

The results of the question concerning summer vacation elicited the most negative responses. Pretest and post-test scores by grade level include: 2.5 compared to 2.3 for 4 th $/ 5$ th graders;

2.6 compared to 2.0 for 5th/6th graders (elementary school), 2.4 compared to 2.3 for 5 th/6th graders (middle schools), 2.4 compared to 2.0 for 6th/7th graders, and 2.3 compared to 1.9 for 7 th/8th graders. The attitude scores ranged from a high of 2.6 at the beginning of 6th grade to a low of 1.9 at the end of eighth grade.

The question about "going to a bookstore" elicited the most positive responses of all the questions: a range of scores from highs of $3.5-3.1$ for pretest scores and a low of 2.6 for the posttest score at the end of eighth grade.

The role of the public library, and the need for the school to cooperate with them, in encouraging participation in summer reading clubs and programs, would appear to be of vital importance. Earlier studies, including Barbara Heyns study in 1978, have indicated that the most influential activity on students' academic development at these grade levels is reading during the summer (and use of the public library), even more than going to summer school or taking a trip with the family. Yet we have not built on this knowledge to create stimulating summer reading programs which are attended by many of the most "at-risk" students. Teachers and school librarians must work with the public library, the families, and the students themselves to encourage participation in summer reading.

These "at-risk" students, on the other hand, feel most positive about "going to a bookstore." We need to ask why that is so attractive an activity? It is not difficult to understand part of the appeal of the bookstore as a leisure time activity-attractive displays of popular and new books with enough copies for anyone who visits, the way books are displayed and arranged, the attractiveness of new books, the stress on popular authors and series, etc. Today, bookstores often 
have cafes, programs for children, and profitable sales-at least for the chain bookstores. Which of these activities can the school library (and public library) "copy"? Certainly, they could buy more copies of popular materials, more paperbacks, but even more importantly, they could merchandise books more effectively through displays, grouping books by genres (as well as popular authors), and provide many attractive and annotated Booklist.

Unfortunately, this standardized instrument did not ask, how do you feel about going to the school library? (or the public library?) There is no way to make direct comparisons. Could school librarians be seen as "credible" readers' advisors both in formal ways (as booktalkers and providing Booklist) and in informal ways-let me tell you about a great new book that has just arrived.., or since you enjoyed that book so much, are you aware of the other books by that author.., or, on that genre.., or on the same theme? Are school librarians seen by teachers as resources for "knowing good books"? Is the school librarian viewed as a reading role model for students and teachers alike? And perhaps, most of all, do they provide access in both the library and the classroom to books that appeal to students to read for fun as well as for specific assignments?

\section{FUTURE RESEARCH}

There are several results that have raised questions for future research. Why is it that almost all studies of student reading attitudes show that they become less positive by the end of the year, and at each grade level? What are the differences between what teachers (and the curriculum) expect during the primary grades (when attitudes are generally positive) and the upper elementary grades when attitudes toward school reading generally decline? What are the unique factors in the schools that have students with the most positive attitudes toward reading? Some of these factors can be teased out of the current studies in comparing the case study schools with the attitudinal results for students in these schools. These studies are ongoing.

\section{REFERENCES}

Alexander, J. E. and Filler, R. C. (1976). Attitudes and reading. Newark, DE.: International Reading Association.

Anderson, R. C., Hiebert, E.H., Scott, J.A., \& Wilkinson, I.A.G. (Eds.) (1985). Becoming a nation of readers. Washington, DC: The National Institute of Education.

Anderson, R. C., Wilson, P.T., \& Fielding, L.G. (1988). Growth in reading and how children spend their time outside of school. Reading Research Quarterly 23(3), 285-303.

Bromley, K., Winters, D., \& Schlimmer, K. (1994). Book buddies: Creating enthusiasm for literacy learning. The Reading Teacher 47, 392-399.

Carlsen, G. R. \& Sherrill, A. (1988). Voices of readers: How we come to love books. Urbana, IL: National Council of Teachers of English.

Cothern, N. and Collins, M. (1992). An Exploration: attitude acquisition \& reading instruction. Reading Research and Instruction 31, 84-97.

Cramer, E. H. \& Castle, M. (Eds.) (1994). Fostering the love of reading: the affective domain in reading education. Newark, DE: International Reading Association.

Cullinan, B. W. (Ed.) (1987). Children's literature in the reading program. Newark, DE: International Reading Association.

Dulin, K. L. (1979). Assessing reading interests of elementary \& middle school students. In D.L Monson \& D.K. McClenathan (Eds.). Developing active readers: Ideas for parents, teachers, \& librarians. Newark, DE: International Reading Association.

Estes, T. H. (1971). A Scale to measure attitudes toward reading. Journal of Reading 15 (2), 135138.

Johnson, C. S. \& Gaskin, J. (1992). Reading attitude: Types of materials \& specific strategies. Reading Improvement 29, 133-139.

Lewis, J. (1983). A Reading attitude inventory for elementary school pupils. In J. Thomas \& R.M. Loring (Eds.). Motivating children \& young adults to read (pp. 7-12). Phoenix, AZ: Oryx Press. 
Liska, A. E. (1984). A Critical examination of the causal structure of the Fishbein/Ajzen attitudebehavior model. Social Psychology Quarterly 47, 61-74.

McKenna, M. \& Kear, D. J. (1990). Measuring attitude toward reading: A new tool for teachers. The Reading Teacher 43, 626-639.

McKenna, M. C., Kear, D. J., \& Ellsworth, Rolph A. (1995). Children's attitudes toward reading: A national survey. Reading Research Quarterly 30(4), 934-956.

McKenna, M. C. (1994). Toward a model of reading attitude acquisition. In E.H. Cramer \& M. Castle (Eds.). Fostering the love of reading: the affective domain in reading education. (pp. 18-40). Newark, DE.: International Reading Association.

Mathewson, G. C. (1994). Model of attitude influence upon reading \& learning to read. In R.B. Ruddell, M.R. Ruddell, \& H. Singer (Eds.). Theoretical models \& processes of reading (4th ed., pp. 1131-1161). Newark, DE.: International Reading Association.

Mullis, I. V. S., Campbell, J. R. \& Farstrup, A. E. NAEP 1992: Reading report card for the nation \& the state. Washington, DC: U.S. Department of Education.

Pajares, M. F. (1992). Teachers' beliefs \& educational research: Cleaning up a messy construct. Review of Educational Research, 61, 307-322.

Rajecki, D. W. (1990). Attitudes. (2nd ed.) Sunderland, MA: Sinauer Associates.

Ruddell, R. B. \& Speaker, R. (1985). The Interactive reading process: a model. In H. Singer \& R. B. Ruddell (Eds.). Theoretical models \& processes of reading (3rd ed., pp. 751-793). Newark, DE: International Reading Association.

SPSS Advanced statistics, 7.0 update manual, 1996, 1-2.

Stahl, S. A., McKenna, M.C. \& Pagnucco, J. (1994). The Effects of whole language instruction: an update \& a reappraisal. Educational Psychologist, 29(4), 175-185.

Stahl, S.A. \& Miller, P.A. (1989). Whole language \& language experience approaches to beginning reading: quantitative research synthesis. Review of Educational Research 59, 87-116.

Summers, E. G. (1977). Instruments for assessing reading attitudes: a review of research \& bibliography. Journal of Reading Behavior 9, 137-165.

Tunnell, M., Calder, J. E. \& Justen, Joseph E. (1988, Summer). A Short form reading attitude survey. Reading Improvement, 146-151.

Walberg, H. J. \& Tsai, S. L. (1985) Correlates of reading achievement \& attitude: a national assessment study. Journal of Educational Research 78, 159-167. 